\title{
perifèria
}

Número 5, Diciembre 2006

www. periferia.name

\section{La imaginación autobiográfica ${ }^{1}$}

\author{
Carles Feixa Pàmpols- Universitat de Lleida / Institut Català d'Antropologia²
}

\section{Resumen}

La imaginación autobiográfica es fruto de la cooperaración creativa entre un sujeto y un investigador, implicados en la construcción de una escritura sobre la subjetividad. Aunque la forma pueda ser literaria, el contenido es cognoscitivo: leer una historia social a través de una historia de vida. El presente artículo repasa la historia del método biográfico en ciencias sociales, presentando diez autores y obras escogidos como indicadores de otras tantas tradiciones nacionales, paradigmas teóricos y estrategias narrativas. Cada uno de estos modelos representa concepciones distintas de la historia de vida, respectivamente, como memoria de los vencidos, crónica de éxodos, biograma, relato cruzado, novela, película, intercambio oral ritualizado, hagiografía contracultural, antibiografía, y dialógica.

\begin{abstract}
The autobiographical imagination is the creative cooperation between a subject and a researcher, who are engaged in the construction of a writing on subjectivity. Even if the form can be literary, the content is cognoscitive: reading a social history through a life story. The present article look to the history of the biographical method in social sciences, showing ten authors and works selected as indicators of such national traditions, theoretical paradigms and narrative strategies. Each one of those models represent different conceptions of life histories as, respectively, memory of defeated, diasporic chronicle, biogram, crossed story, novel, film, ritualized oral exchange, countercultural hagiography, antibiography and dialogy.
\end{abstract}

\footnotetext{
${ }^{1}$ Este artículo es una versión revisada y aumentada de un texto publicado originalmente en catalán en la revista de historia L'Avenç ( $n$ o 252, 2000: 16-29). Aunque el texto se base en una revisión bibliográfica, mi aproximación al contexto debe mucho al contacto directo con algunos de los autores reseñados (Sandro Portelli, Maurizio Catani, Oriol Romaní, Ignasi Terradas, Joan Frigolé y Ricard Vinyes), alguno de los cuales me facilitaron reseñas y lecturas complementarias, así como la visita a escenarios vitales de otros protagonistas (el museo del departamento de antropología de Berkeley donde se conservan los objetos de Ishi, las vecindades de México donde vivieron los Sanchez). También quiero agradecer a J oan Prat por sus ánimos para traducir el texto al castellano (en una versión que ha acabado siendo casi por completo diferente). El artículo esta dedicado a los alumnos de la asignatura "Historias de vida" del doctorado en antropología de la UAB, y al profesor Ramón Valdés, en cuyo libro de homenaje debía aparecer inicialmente.

${ }^{2}$ Enviar correspondencia a: (feixa@geosoc.UdL.es)
} 


\section{perifèria}

Número 5, Diciembre 2006

www. periferia.name

\section{Prólogo}

“La imaginación sociológica nos permite captar la historia y la biografía y la relación entre ambas dentro de la sociedad" (Mills 1977: 25-6).

“El auténtico entorno de una declaración, el entorno en el que vive y se forma, es la heteroglosia dialógica, anónima y social como el lenguaje, pero al mismo tiempo concreta, tan repleta de contenido específico y matices como una declaración individual" (Bakhtin 1994: 326). ${ }^{3}$

La imaginación autobiográfica es la capacidad para cooperar en la construcción de una escritura biográfica abierta y sugestiva, capaz de ayudar a comprender un tiempo y un espacio humano, de leer una historia social a través de una historia de vida. Por ello remite a la imaginación sociológica de la que habló C. Wright Mills [1959], y a la imaginación dialógica a la que se refirió Mijail Bakhtin [1981]. Huelga decir que el título de este ensayo está inspirado en la obra de estos dos autores. En The Sociological Imagination, Mills defendió la necesidad de volver a la tríada biografía-historia-sociedad, para poder entender mejor la estructura social presente en cada historia individual, pues las ciencias sociales están condenadas a la vacuidad si, al concentrarse en técnicas sofisticadas, olvidan a las personas reales y renuncian a la creatividad (a la "artesanía intelectual"): "Ni la vida de un individuo ni la historia de una sociedad pueden entenderse sin entender ambas cosas" (1977:23). En The Dialogic Imagination, Bakhtin mostró que la comprensión del espacio y el tiempo de una novela (pero lo mismo serviría para la autobiografía) dependen de la capacidad heteroglósica (es decir, de la capacidad de hacerse eco de otras voces, para interpretarla no sólo en función del texto sinó también del contexto). Esta capacidad surge siempre de un doble diálogo: un "dialogismo interno", en primer lugar, fruto de la interacción del sujeto con su propia memoria; un "dialogismo externo", en segundo lugar, fruto de la interacción con el entorno social representado por el auditorio (o por el investigador que pregunta, transcribe e interpreta lo hablado): "La declaración vivida, habiendo tomado sentido y forma

\footnotetext{
3 La traducción castellana de las citas originales en inglés, francés e italiano que aparecen en este texto es del autor. Dialógico y heteroglosia y son neologismos utilizados por Bakhtin (1994) para referirse al diálogo y la pluralidad de voces como esencia de la comunicación verbal y del relato (Cfr. el Glosario de la versión inglesa de su obra a cargo del editor M. Holquist).
} 


\section{perifèria}

Número 5, Diciembre 2006

www. periferia.name

en un momento histórico particular en un medio social específico, no puede evitar deshacer centenares de vívidos hilos dialógicos, tejidos por conciencias socioideológicas en torno al objeto mismo de la declaración; no pueden evitar participar activamente en el diálogo social" (1994:276). ${ }^{4}$

El presente artículo repasa la historia de los usos del material autobiográfico en ciencias sociales, presentando algunas obras que, desde principios del siglo XX, han utilizado las narrativas personales en la generación de discursos académicos sobre el cambio social. Naturalmente, se trata de un recorrido parcial, dado que los autores y las obras han sido escogidos como indicadores de disciplinas académicas, tradiciones nacionales, paradigmas teóricos y estrategias narrativas tan heterogéneas como fecundas. Pero dibuja un muestrario de la creatividad practicada por antropólogos, sociólogos, historiadores y literatos en la búsqueda de formas nuevas de comunicar las palabras de vida que les ofrecieron informantes pertenecientes a grupos sociales variados. Hemos escogido diez obras que presentan las historias de vida como, respectivamente, memoria de los vencidos, crónica de éxodos, biograma, relato cruzado, novela, película, intercambio oral ritualizado, hagiografía contracultural, antibiografía, y dialógica. Para cada una de ellas analizaremos el contexto histórico, los pretextos teórico-metodológicos y el texto resultante. ${ }^{5}$

\section{La historia de vida como memoria de los vencidos}

"Ishi vivió durante muchas lunas como un hombre de museo entre los hombres del museo. La muerte le llegó tal y como él deseaba: en el watgurna-museo, con sus amigos. El Majapa y los hombres del museo

\footnotetext{
${ }^{4}$ La literatura sobre fuentes orales en castellano es ya cuantiosa. Además de los artículos incluídos en la revista Historia, Antropología y Fuente Oral, debemos destacar los readers de Balán (1974), Marinas \& Santamaría (1993) y la excelente revisión bibliográfica de Pujadas (1992), cuya reedición nos gustaría reclamar desde aquí.

${ }^{5}$ La selección es, por supuesto, parcial, pues hemos dejado de lado algunas obras que han despertado una notable polémica en la antropología internacional, contribuyendo al debate sobre la renovación de las formas de escritura etnográfica. Nos referimos, por ejemplo, a algunas obras surgidas de Africa, como el clásico de Vansina (1967) sobre el concepto de tradición oral, y las aportaciones más recientes de Crapanzano $(1980,1985)$. El poder de la oralidad en la cultura africana y su traslación a la memoria de la esclavitud, ha sido objeto de biografías noveladas como Raíces (cuya conversión en serie televisiva constituyó todo un fenómeno).
} 


\section{perifèria}

Número 5, Diciembre 2006

www. periferia. name

liberaron su Espíritu, siguiendo el viejo procedimiento yahi. Y por esta razón cuidaron que Ishi llevara consigo las cosas que un cazador yahi tiene que llevarse del Mundo de los Vivos para el viaje hacia el Oeste: su mejor arco y cinco buenas flechas; una cesta de harina de bellotas, suficiente para cinco días -su hatillo de tesoros" (Kroeber 1961: 192-3).

El 25 de marzo de 1916, un indio moría de tuberculosis en el hospital de la Escuela de Medicina de la Universidad de California, situado cerca del Golden Gate Park, en San Francisco. Le acompañaban, además del médico, el equipo del Museo de Antropología, que estaba situado al lado del hospital, donde había pasado los últimos cinco años de su vida. Le Ilamaban Ishi (nombre que en su lengua significa Hombre) y lo habían encontrado en 1911, muerto de hambre, frío y agotamiento, escondido en un corral cerca de una ciudad minera al norte de California. Cuando fue hallado, no hablaba ni una palabra de inglés ni de castellano, ni tampoco ninguna de las lenguas indígenas conocidas. Después de pasar unos días en la carcel (oficialmente para protegerle de los blancos), el Departamento de Asuntos Indios aceptó que el Museo de Antropología se hiciera cargo de él: los últimos años de su vida los pasó en una de las estancias del museo, como una pieza viva extraordinariamente valiosa.

Cuando le encontraron, Ishi tenía unos 50 años; era, literalmente, el último de su tribu -los yahi-, pertenecientes a la cultura yana, que habían ocupado aquellos valles desde hacía más de dos milenios, dedicados a la caza, pesca y recolección: eran los primeros y más antiguos pobladores de la región. La tribu, después de años de guerrilla, había sido prácticamente exterminada a manos de los blancos, el 1865 (el recuerdo de esta masacre ocupa un lugar central en el relato de Ishi). Pero según parece quedaron algunos supervivientes que se refugiaron en unos desfiladeros salvajes del río Deer, donde malvivieron huyendo de los blancos durante casi medio siglo más. En 1870 fueron vistos por última vez dos hombres, dos mujeres y un niño (probablemente Ishi). No volvería a haber noticias suyas hasta 1909, cuando los trabajadores de una empresa eléctrica tuvieron contactos con una anciana (la madre de Ishi), que había huido presa del miedo. La fiebre del oro había atraído nuevos colonos, y los últimos aborígenes tuvieron que ir 


\section{perifèria}

Número 5, Diciembre 2006

www. periferia.name

retrocediendo, hasta que uno a uno, todos fueron muriendo y sólo quedó el niño, que se había convertido en un viejo enfermo y perdido. Una mañana decidió dirigirse a la tierra de los rostros pálidos, con la esperanza de que le disparasen un tiro y pudiera así finalmente reunirse con sus antepasados en el Oeste eterno. ${ }^{6}$

El director del Museo y del Departamento de Antropología de la Universidad de California en Berkeley era por aquel entonces Alfred L. Kroeber, se ocupó de Ishi e intentó documentar la etnia de la cual provenía. Por eso permitió que el indio viviera en el museo, donde él y su mujer, Theodora Kroeber, lo cuidaron y mantuvieron con él largas conversaciones en las que evocó su vida de fugitivo. Muchos años después, en 1961, la señora Kroeber aprovechó todo este material para escribir la que llegaría a ser la biografía más popular de los indios americanos: Ishi in two worlds, que pronto se convertiría en un auténtico best-seller. El libro era una de las últimas muestras de la pasión por las "biografías de los últimos salvajes" que invadió Estados Unidos desde medianos del siglo XIX. Desde la publicación de la biografía de una india cherokee cristianizada, a cargo de Rufus Anderson, en 1825, una auténtica obsesión por recoger la memoria de los vencidos recorre el país. Durante el resto del siglo se publican centenares de libros sobre "individuos distinguidos entre los nativos norteamericanos como oradores, guerreros, líderes políticos o otras habilidades destacadas", tal y como predicaba una de las compilaciones. En general se trataba de publicaciones sin finalidad científica, elaboradas por terceras personas - viajeros, literatos, agentes gubernamentales o aficionados- que "traducían" y "rehacían" las experiencias de los protagonistas, ya que la mayor parte de los testimonios recogidos son antiguos guerreros 0 chamanes, preferentemente aculturalizados y cristianizados, testimonio de los progresos de la civilización. No será hasta el primer cuarto del siglo XX cuando este movimiento espontáneo tenga efectos en la disciplina antropológica: la publicación de testimonios de los "últimos de la tribu" se reviste de perfiles científicos. Pero los

\footnotetext{
${ }^{6}$ Las referencias a esta historia provienen de la prensa de la época, y fueron resumidas en un artículo de Alfred L. Kroeber, "Ishi, the Last Aborigine", publicado en 1912 y reeditado en un volumen que recoge toda la documentación periodística, histórica y antropológica sobre el caso: Heizer \& Kroeber 1979. Las pertenencias de Ishi están aún hoy en día expuestas en el museo, trasladado a la sede del Departamento de Antropología de Berkeley, el cual tiene una sala dedicada a su memoria.
} 


\section{perifèria}

Número 5, Diciembre 2006

\section{www.periferia.name}

protagonistas siguen siendo los mismos: ancianos aculturados, antiguos líderes (algunos famosos, como Gerónimo o Sitting Bull), que recuerdan los gloriosos tiempos del pasado, cuando aún no habían sido vencidos por el quinto de caballería (los conflictos de la vida en las reservas no son, casi nunca, objeto de indagación). Las modalidades de la recolección siguen un mismo patrón: el antropólogo "reescribe" en forma de "memoria" los recuerdos que el informante le ha facilitado oralmente; el intercambio se produce en condiciones de extrema asimetría; se presta escasa atención a las formas orales del relato y nunca se explicitan las condiciones de recogida de los datos. También son semejantes las finalidades perseguidas: rescatar un patrimonio en vías de desaparición (y de paso, limpiar la mala conciencia de los vencedores). ${ }^{7}$

Ishi es, pues, una muestra tardía de esta pasión autobiográfica, y expresa perfectamente sus luces y sus sombras. El relato está redactado en forma novelada, sin explicitar su origen oral, si las conversaciones fueron espontáneas o fruto de un cuestionario, si fueron grabadas, en qué lengua se produjo el intercambio, cómo se transcribió y elaboró, etc. El narrador no es el protagonista, sino que los hechos aparecen narrados en tercera persona, en un tono poético aunque distanciado, que persigue provocar la identificación con las vivencias de este ser indefenso, sin olvidar la distancia cultural que subraya el exotismo del que narra. El deseo esteticista refuerza los perfiles románticos con los que la autora describe a este "buen salvaje". A partir de finales de los años 60, sin embargo, aparecen nuevos ejemplos de producción biográfica -que ahora tienen como sujeto a "nativos americanos" y representantes de las "primeras naciones" -donde los

\footnotetext{
${ }^{7}$ Se trata de una pasión literaria que coincidió con la pacificación de las culturas indias aniquiladas por la "paz blanca", simbolizada en la matanza de Woounded Knee (1890). Este interés se expresaba también en la asistencia a los Wild West Shows - como los protagonizados por Buffalo Bill- y en la compra de novelas por entregas que pintaban a los indios como brutales salvajes violadores o bien como seres inocentes necesitados de protección. Alguno de estos relatos sería llevado a la gran pantalla posteriormente, como Geronimo's Story of His Life (Barret 1906) y The Princess Pocahontas (Watson 1916). Con posterioridad, aparecieron contribuciones más serias a cargo de antropólogos, como la famosa autobiografía de un indio hopi Sun Chief (Simmons 1942). Cfr. Brandes 1983; Langness \& Frank 1985; Pujadas 1992.

${ }^{7}$ Una contribución contemporánea notable, con respeto al caso de los indígenas lationamericanos, es la obra de el antropólogo mexicano Ricardo Pozas Juan Pérez Jolote (1952). Se trata de un fascinante relato de un hombre chamula, que no evita hablar de los conflictivos contactos entre indígenas y criollos.
} 


\section{perifèria}

Número 5, Diciembre 2006

www. periferia.name

protagonistas asumen su Yo para reivindicar sus derechos civiles y exponer las injusticias de su vida presente en las reservas o en medio de la sociedad blanca: las mujeres, los jóvenes y los mestizos son los adalides de un movimiento revitalista que recupera el sentido "político" del discurso autobiográfico, como refugio y emblema de una identidad en proceso de reconfiguración.

\section{La historia de vida como crónica de éxodos}

"A efectos de análisis sociológico, la superioridad de los documentos vitales sobre cualquier otro tipo de material se hace evidente cuando pasamos de la caracterización de datos simples a la determinación de hechos, ya que no hay forma más segura y eficiente de buscar las causas reales de un acontecimiento social entre sus innumerables antecedentes, que analizar el pasado de los individuos gracias a cuya actuación ocurrieron estos hecho" (Thomas \& Znaniecki 1978: 295).

El 10 de enero de 1911 -el mismo año en que encontraron a Ishi- Helena Dawrowskis, una campesina polaca emigrada a los Estados Unidos, escribía desde Wilmington (Delaware) a su hermana Teófila, que se había quedado en Polonia, explicándole sus problemas de adaptación al nuevo país. Su padre había emigrado algún tiempo atrás, y la familia se había ido reagrupando, pero la carta tiene un tono de añoranza por la solidaridad perdida: “Querida hermana: ... recibí la carta con la Hostia [consagrada] y agradezco que pensaras en mí. Ahora, querida hermana y cuñado, no os enfadéis si no os escribo mucho, pero yo no sé escribir y hasta que no se lo pido a alguien que me la escriba [la carta] el tiempo pasa, pero intentaré contestaros a menudo. Me preguntáis cuánto ganamos yo y mis chicos. Mi marido trabaja en una fundición, gana 9, 10, 12 rublas [dólares], y los chicos ganan 4 o 5 rublas. Querida mía, en América no se está mejor que en nuestro país: quien tiene, vive bien; quien no tiene, sufre miseria. Yo no sufro miseria, a Dios gracias, pero tampoco disfruto demasiado. Mucha gente en nuestro país piensa que en América todos son felices. No, es como en nuestro país, y las iglesias son como las nuestras, y en general todo es igual. Nos despedimos deseándoos lo mejor" (Thomas \& Znaniecki 1978: 154-5). 


\section{perifèria}

Número 5, Diciembre 2006

www.periferia. name

Entre 1880 y 1910 aproximadamente dos millones de polacos emigraron a América. Muchos de ellos, después de pasar Ellis Island, tenían Chicago como primer destino. La ciudad se había convertido en lugar de llegada de movimientos migratorios nacionales y transnacionales, que la convirtieron en un paradigma del que más tarde se conocería como melting pot. Varios éxodos de carácter religioso, político y económico reunieron en Chicago a una multiplicidad de minorías étnicas y grupos dispares, que convirtieron la ciudad -que doblaba su población cada 15 años- en un auténtico laboratorio para la investigación social. No es entonces extraño que su universidad fuera cuna de una de las escuelas más famosas de sociología. En 1913 Florian Znaniecki, un sociólogo polaco que había sido expulsado por razones políticas de la universidad de su país de origen, y que trabajaba para una asociación de apoyo a los emigrantes que querían viajar a los Estados Unidos, se encontró con William I. Thomas, un investigador norteamericano que trabajaba en la Universidad de Chicago. Juntos decidieron emprender un monumental estudio sobre el éxodo de los campesinos polacos hacia la nueva tierra prometida. Pero en lugar de basarse en fuentes públicas, hasta ese momento privilegiadas por las ciencias sociales - registros oficiales, noticias de prensa, discursos gubernamentales, etc.- optaron por centrarse en los "documentos personales" producidos por los mismos sujetos, principalmente las cartas que los inmigrantes escribían a sus familias de origen. El resultado fue The Polish Peasant in Europe and America, editada en 5 volúmenes entre 1918 y 1920, que con el tiempo llegaría a convertirse en una obra de referencia para todos los científicos sociales. ${ }^{8}$

Mientras que Ishi evoca la imaginación autobiográfica aplicada al estudio de los vencidos por el progreso inexorable de la civilización, The Polish Peasant relata el éxodo de los emigrantes atraídos por este mismo progreso. El postulado con el que empiezan su famosa "introducción metodológica" se ha convertido en célebre: el documento personal representa el "tipo de dato más perfecto con el que los sociólogos pueden esperar trabajar". La teoría social tiene que tener en cuenta dos

\footnotetext{
${ }^{8}$ Por desgracia, la obra ha sido mucho más citada que efectivamente leída (entre otras cosas, por su extensión y por no existir traducciones). Cf. la introducción de Zaretsky (1978) a una reciente edición abreviada, que es la que se utiliza aquí.
} 


\section{perifèria}

Número 5, Diciembre 2006

\section{www.periferia.name}

tipos de datos: los que provienen de los elementos objetivos de la vida social (a los que llaman 'valores') y los rasgos subjetivos de los miembros del grupo social (a los que llaman 'actitudes'). Valores y actitudes no se pueden estudiar de forma separada, y por eso se recomienda la utilización de "documentos vitales o personales", como por ejemplo cartas, diarios personales, registros criminales, historias de vida, etc. La utilización adecuada de estos documentos, a efectos de "generalización nomotética", exige establecer criterios de representatividad, aunque el proceso sea mucho más complicado que en las ciencias naturales (ya que no es fácil aislar los fenómenos). Los autores proponen resolver este dilema a través de un cambio de perspectiva metodológica: en lugar de un camino inductivo, los documentos personales requieren un proceso deductivo que tiene que perseguir la síntesis de aquello concreto a partir de sus elementos abstractos, es decir, la reconstrucción del proceso completo de cada evolución personal. ${ }^{9}$

Más que sus contribuciones teóricas, el impacto perdurable del libro se debe a su propuesta metodológica, basada en la vindicación de los "documentos personales" como fuentes primarias de investigación científica. La paradoja es que en el libro, de historias de vida propiamente dichas, sólo hay una: la extensa autobiografía de un joven inmigrante recogida en el cuarto volumen. Se trata de un relato escrito por el propio testimonio, precedido por una introducción en la que teorizan sobre el papel del "carácter" en la organización vital, pero no dicen casi nada de las condiciones de recolección del relato, ni aplican su propuesta de reconstruir una "síntesis" de esta trayectoria personal. En realidad, la obra se centra en otro tipo de documentos personales: las cartas. Los campesinos polacos escribían numerosas y largas cartas, aunque era una tarea a menudo pesada debido a su precaria alfabetización. Lo que Ilaman "carta de saludo" (bowing letter) está normalmente dirigida a un miembro ausente de la familia, y su función es manifestar la

\footnotetext{
9 Las 2244 págs. del libro están estructuradas en 4 partes: en la primera se analiza la organización primaria de la familia campesina; en la segunda se estudia el proceso de organización y desorganización en Polonia; en la tercera se estudia el mismo proceso pero en América; la cuarta parte recoge la autobiografía de un inmigrante, con una densa introducción metodológica que sirve de justificación. Thomas y Znaniecki explican la sociología de los inmigrantes por el rompimiento de la sociedad tradicional, en particular del sistema familiar, y mantienen que la forma de vida campesina se había empezado a "desorganizar" antes de su emigración a América.
} 


\section{perifèria}

Número 5, Diciembre 2006

www. periferia.name

persistencia de la solidaridad familiar, con una estructura y composición muy estandarizadas. El libro analiza centenares de estas cartas, agrupadas en series (desde jornaleros hasta la pequeña nobleza rural), que utilizan para reseguir el proceso de organización y desorganización social de los campesinos emigrados.

La aproximación de Thomas y Znaniecki se basa en considerar los documentos personales como unos documentos "naturales" en un doble sentido: por haber sido producidos espontáneamente y por describir con precisión "naturalista" las condiciones de vida de los sujetos de los que hablan. Ambos supuestos son engañosos. Por un lado, los relatos no siempre eran espontáneos, ya que la intervención del investigador era notable en la selección y motivación (la mayoría de las cartas fueron recogidas después de un anuncio en un periódico polaco en el que se prometía una remuneración). Por el otro, las descripciones del entorno vital no eran tampoco del todo "naturales", ya que los aspectos autojustificativos eran notables, por no hablar del mecanicismo implícito en la teoría sobre la organización y desorganización sociales típica de la escuela de Chicago. En cualquier caso, su ejemplo lo siguieron otros chicagoans, interesados en revelar la cara oculta del sueño americano: Nels Anderson recogió relatos de hoboes (nómadas urbanos); Harvey Zorbaugh recogió la historia de vida de una mujer que emigró de Kansas a Chicago para estudiar música y que terminó trabajando de taxi-dancer en un local de cuestionada reputación; Clifford Shaw recogió el relato autobiográfico "en sus propias palabras" de un joven delincuente, al que llamó Jack-Roller. En la introducción de esta última obra, Ernest Burgess, inspirador de la escuela de ecología humana junto con Robert Park, justifica la superioridad de la historia de vida sobre las entrevistas estructuradas por el hecho de que "una persona narra su propia historia a su manera, una narrativa toma el carácter de una crónica, una defensa, una confesión, una auto-análisis... el relato y la escritura de la propia historia de vida es en si mismo parte del tratamiento". Se sugería así otra lectura 


\section{perifèria}

Número 5, Diciembre 2006

www. periferia.name

del uso de materiales biográficos, que ya había descubierto Freud: su virtualidad terapéutica. ${ }^{10}$

\section{La historia de vida como biograma}

“Los biogramas son relatos de vida escritos bajo demanda por personas que pertenecen a un grupo social seleccionado, y de acuerdo con direcciones específicas para contener y conformar el objetivo de obtener datos masivos (...) Más que cualquier otro método, el uso de biogramas requiere de iniciativa, habilidad, ingenuidad e imaginación por parte del investigador" (Abel 1947: 114-117).

En 1936 se publicó en el Praysposobienia Rolniczego, una revista polaca de formación agrícola, el anuncio de un Concurso de Autobiografías destinado a los jóvenes campesinos, con el siguiente lema "Descripción de mi vida, trabajo, pensamientos y deseos". La convocatoria, auspiciada por el Instituto para la Cultura del Pueblo, sugería las siguientes cuestiones: “¿Hacia donde van los pueblos polacos? ¿Qué corrientes agitan a los jóvenes rurales? ¿Cuáles son sus pensamientos, deseos y fines? ¿Cómo ven la situación actual del campo en general, y de los pueblos en particular? ¿Cómo interpretan este panorama y en qué medida quieren cambiarlo y reconstruirlo?" (citado en Abel 1947: 113). Para responder a estas preguntas, el periódico proponía a los “campesinos jóvenes hijos e hijas" que redactaran un texto personal en dos partes: en la primera debían relatar la historia de su vida desde su nacimiento hasta el presente, incluyendo la descripción de su familia, pueblo, infancia, escolaridad, trabajo, participación en asociaciones, etc; en la segunda se les pedía que explicaran qué pensaban de su propia situación y de su relación con la comunidad, la nación y el estado. Los mejores recibirían un premio en metálico (los criterios de calidad no se basarían en la calidad literaria sino en la sinceridad y riqueza de los datos). La convocatoria fue un gran éxito: se recibieron 1544 relatos, que permitieron al sociólogo J. Chalasinski publicar en 1938 los 4

\footnotetext{
${ }^{10}$ Anderson 1923; Zorgbaugh 1929; Shaw 1930; Cfr. Plumer 1983, Pujadas 1992. Todo ello sirvió para recrear un nuevo género de escritura científica "naturalista", que debía mucho a la literatura y al periodismo (otra vertiente sería la novela negra, como la famosa obra de Truman Capote A sangre fría, inspirada en un asesino real).
} 


\section{perifèria}

Número 5, Diciembre 2006

www. periferia. name

volúmenes de su monumental Mlode pokolenie chlopow (La joven generación polaca). El autor era discípulo de Florian Znaniecki, que en 1921 había regresado a Polonia para fundar un Instituto de Sociología en la Universidad de Poznan, desde donde promovió una serie de investigaciones sobre la vida polaca en las que aplicó su fe en los documentos personales para estudiar distintos grupos sociales: habitantes de la frontera germano-polaca, criminales, trabajadores, subempleados, científicos, etc. Los resultados impresionaron tanto al gobierno polaco que instituyó una política oficial para coleccionar datos biográficos complementarios a los de la Oficina de Estadística. ${ }^{11}$

El mismo 1938, el sociólogo norteamericano Theodore Abel había publicado un libro sobre el auge del nazismo en Alemania (Why Hitler Came into Power), para el que se basó en entrevistas a miembros del partido nazi. Este estudio le convenció de las potencialidades de los datos personales, pero también de sus límites: para ser generalizables, estos datos debían ser masivos, sistemáticos, comparables y restringidos a un grupo social delimitado. En 1947, tras el lapso bélico, Abel publicó en el prestigioso American Journal of Sociology un artículo fundamental titulado "The Nature and Use of Biograms", en el que se inspiraba en el estudio de Chalasinski para proponer una nueva fundamentación del método biográfico. Para ello inventó un neologismo - biograma- cuyo significado no venía de su etimología sino una analogía lingüística: si el habla de cada individuo no se entiende sin la gramática de su lengua, la historia de vida resulta ininteligible sin referirse al biograma que comparte con otros miembros de su grupo social. Partiendo de la creencia en la unidad de la ciencia, podían existir diversos "modelos" de interpretación de los datos: por una parte, el "modelo máquina", fundamental en ciencias naturales, que se basa en la comprensión de los mecanismos de la vida física; por otra parte, el "modelo relato", fundamental en ciencias humanas, que se basa en la comprensión de los dramas de la vida social (en la construcción del

\footnotetext{
${ }^{11}$ La tradición polaca de los concursos autobiográficos fue iniciada por Znaniecki en 1921 y experimentó un gran auge hasta la II Guerra Mundial, teniendo continuidad en la posguerra (Szczepanski 1978; Pujadas 1992). En Catalunya TV3 y el departamento de Antropología de la Universitat de Barcelona hicieron hace unos años una convocatoria parecida, bajo el lema Explica'ns la teva vida, que tuvo un éxito notable y se tradujo en serie televisiva y libro (VVAA. 2001).
} 


\section{perifèria}

Número 5, Diciembre 2006

www. periferia.name

guión de un relato). Las diferencias entre ambos modelos son de grado, pero no de naturaleza: los científicos sociales pueden aspirar a establecer generalizaciones equivalentes a las de los físicos con una única condición: que sus descubrimientos sean validados por tests objetivos.

Abel distingue tres "modelos" de relato de vida. La "autobiografía", en primer lugar, es un relato escrito por iniciativa del propio sujeto (político, héroe, santo, obrero), con formas heterogéneas (hagiografía, memoria, confesión, autoanálisis), normalmente con objetivos de calidad literaria y ejemplaridad moral, y que tiene como uno de sus fines perpetuar la memoria del autor. El "biograma", en segundo lugar, es lo contrario: un relato escrito por iniciativa de una tercera persona (un investigador), con formas más homogéneas (normalmente basadas en un guión más o menos esquemático), sin que predomine la calidad literaria ni criterios de ejemplaridad, y que tienen por objeto la recogida de datos sobre un grupo social particular. La "historia de vida", finalmente, es un relato de vida recogido de la misma forma que el biograma, pero con la única intención de obtener información sobre una persona particular, sin que exista voluntad de generalizar los datos. Aunque la tipología fue criticada por basarse en el uso y no en la naturaleza de los relatos (pues en la práctica las fronteras entre autobiografía y biograma son fluídas), la propuesta era uno de los intentos más sistemáticos de conceptualización del método biográfico.

El objetivo de Abel no es tanto obtener particularidades individuales cuanto "datos de masa" (mass data), que pueden ser útiles en el estudio de los patrones culturales que conducen el comportamiento social. Abel establece varios criterios para los biogramas: ser amplios, estar escritos por personas no sofisticadas, emocionalmente implicadas con los objetivos de la investigación, estar dedicados a problemas de cambio o desarrollo, y la más importante: “los biogramas, siendo datos de masa, son más útiles cuando puede asumirse que hay un común denominador o patrón en el comportamiento de los miembros de un grupo" (1947:116). Abel concluye con una serie de recomendaciones sobre el "manejo" de biogramas por parte de los investigadores: familiarizarse con los datos, abstraer los pasajes relevantes, codificarlos según criterios de edad, educación, ocupación, etc, 


\section{perifèria}

Número 5, Diciembre 2006

www. periferia. name

establecer tablas de correlación según criterios estadísticos, realizar análisis de contenido y, finalmente, el paso más importante: creative thinking. "El orden, regularidad, secuencias repetidas y conexiones recurrentes conducen a cierto tipo de interpretación generalizada. Los procesos mentales implican esencialmente la adaptación de conceptos generales, constructos esquemáticos o patrones de causalidad a datos concretos, individuales (...) No es cuestión de encontrar el patrón sinó de seleccionar los más validos de una serie de patrones alternativos" $(1947: 118) .^{12}$

Las conclusiones de Abel prefiguraban los caminos que emprendería la sociología en las décadas siguientes. Aunque el autor había concebido los biogramas como un instrumento de alcance circunscrito, algunos de sus seguidores pretendieron convertirlo en modelo de historia de vida y no resistieron la tentación de cuantificar lo cualitativo. Entre las aplicaciones prácticas del modelo de Abel, cabe destacar la investigación de Balan et al. (1974) sobre la movilidad social en Monterrey (México). Los autores parten de criticar la deriva cualitativa del método biográfico, condicionado por el "pecado original" de Thomas y Znaniecki de usarlo sólo como suplemento ilustrativo, lo que llevó a la sociología positivista a menospreciarlo por servir solamente para recabar "datos blandos". A continuación reivindican la fecundidad de los datos biográficos para estudios longitudinales sobre fecundidad, migración y fuerza de trabajo. En estos casos, no es posible basarse en relatos largos como los utilizados por los chicagoans, sino en relatos "parciales" focalizados en determinados aspectos o fases de la vida de un individuo, una especie de "esqueleto" vital que compensa la pérdida de calidad por el aumento de la representatividad de la muestra y su capacidad de generalización. En el caso del estudio sobre Monterrey, los autores codificaron un total de 1640 relatos vitales de hombres entre 21 y 60 años de edad, elaborados a partir de un cuestionario con 200 preguntas, focalizados en la historia migratoria y laboral de estos individuos. Lo

\footnotetext{
12 “Los buenos biogramas ofrecen en primer lugar válidas intuiciones interpretativas y materiales ilustrativos, pero pueden ser formalizados y ofrecer datos definibles en términos operativos. Sin embargo, es preciso recordar que los biogramas no son un método autosuficiente, aunque constituyan un instrumento indispensable para los sociólogos en el estudio de los procesos y de las condiciones sociales" (Abel 1947: 117). Sobre el debate en torno al método biográfico que tuvo lugar en la sociología norteamericana en aquellos años, véase Plumer 1983.
} 


\section{perifèria}

Número 5, Diciembre 2006

www. periferia.name

más original fue utilizar de manera sistemática una computadora de gran capacidad (según los parámetros de entonces) para procesar los datos y analizarlos segun modelos multivariables. La codificación se basó en dos operaciones complementarias: una primera perforación de códigos numéricos que correspondían a determinadas variables comparables longitudinalmente (edad, salario, residencia, matrimonio, fecundidad, etc); y una segunda que permitía reconstruir la historia vital completa de cada individuo en la que sólo se perforaban los cambios en el contenido de cada variable. Ello sirvió para construir una ficha que parece un tipo ideal de biograma: en la coordenada horizontal aparece la edad y en la vertical los cambios en tres grandes ámbitos: historia personal (salud, familia, educación), migratoria (lugar y tipo de residencia) y laboral (ingresos, tipo de empresa, cargo) (1974:24). De Poznan a Monterrey, se había pasado de una concepción humanística a otra positivista que, pese a algunos logros, centró sus esfuerzos en fríos análisis formales, olvidando que los protagonistas de la investigación eran personas de carne y huesos. Los progresos de la informática facilitaron una gran sofisticación, aunque quedaran progresivamente en el olvido tanto el concepto de biograma como la otra propuesta de Abel: "iniciativa, habilidad e imaginacion por parte del investigador" (1947:117). ¿lmaginación biogramática? ${ }^{13}$

\section{La historia de vida como relato cruzado}

"La grabadora utilizada para registrar las historias de este libro ha echo posible el advenimiento de un nuevo tipo de literatura de realismo social. Gracias a la grabadora, personas sin preparación, incultas e incluso analfabetas, pueden hablar de ellas mismas y narrar sus observaciones y experiencias de un modo desinhibido, espontáneo y natural. Las historias de Manuel, Roberto, Consuelo y Marta se caracterizan por la simplicidad,

\footnotetext{
13 Otra derivación del biograma es el concepto de "saturación", aplicado por el sociólogo francés Daniel Bertaux a la perspectiva biográfica: "La saturación es el fenómeno por el que, superado un cierto número de entrevistas, el investigador o el equipo tienen la impresión de no aprender ya nada nuevo, al menos por lo que respecta al objeto sociológico de la investigación" (1993: 156-7). Huelga decir que la validez de tal concepto se limita a investigaciones sobre grupos circunscritos, como los artesanos panaderos estudiados por él mismo y su mujer. Su trabajo aporta numerosos datos sobre el proceso de aprendizaje, la emigración de provincia a ciudad, las técnicas de elaboración del pan, las relaciones de producción, las relaciones familiares, pero la dimensión subjetiva de los relatos queda en segundo plano, pues las historias de vida se conciben básicamente como "relatos de prácticas".
} 


\section{perifèria}

Número 5, Diciembre 2006

www.periferia.name

sinceridad y naturaleza directa que distinguen a la lengua hablada, la literatura oral en contraste con la literatura escrita" (Lewis 1964: XXI-XXII).

El día 11 de febrero de 1965, la Sociedad Mexicana de Geografía y Estadística interpuso una denuncia contra el antropólogo norteamericano Oscar Lewis y la editorial Fondo de Cultura Económica, que acababa de publicar la versión castellana de su obra The Children of Sánchez. Según los denunciantes, el libro, que llevaba por subtítulo "Autobiografía de una familia mexicana", contenía "descripciones impúdicas, opiniones calumniosas, difamatorias y denigrantes contra el pueblo de Méjico y sus gobernantes". Para justificarlo, reproducían extensos parágrafos del mismo, en los que el protagonista, bautizado con el seudónimo de Jesús Sánchez, hablaba en un lenguaje directo -grosero según los denunciantes- de la supervivencia diaria, la sexualidad, la violencia, la corrupción de los gobernantes y otros aspectos que afectan a la vida cotidiana de los pobres de México. En el escrito en defensa contra los cargos imputados, los responsables de la editorial justificaban la publicación del libro en los términos siguientes: "A través de varios años tuvo el declarante la oportunidad de escuchar los textos de las entrevistas realizadas a los cinco miembros de la familia llamada Sánchez, mediante las cintas grabadas que el autor obtuvo durante esos años de trabajo con los protagonistas; que también algunos miembros de la Junta tuvieron oportunidad de escuchar... lo que significa haber podido apreciar la técnica de trabajo del autor, que evidentemente ha significado una innovación en los métodos de estudio antropológicos... que se advirtió el problema que podrían plantear los relatos, que en algunos momentos usan palabras que podrían considerarse incorrectas, pero que, juzgando el libro en su conjunto como un testimonio vivo de las formas de vida, de las ideologías, de los ideales, de las costumbres, de los problemas que sufren hombres y mujeres que integran ese medio llamado de 'la cultura de la pobreza', la Junta consideró por unanimidad que la obra debería publicarse íntegramente". ${ }^{14}$

14 “Resolución del procurador General de la República Mexicana” (Anexo incluido en Lewis 1971: 515). La edición inglesa original se publicó en 1961. La obra fue llevada a la gran pantalla por L. Barlett en 1978, en una discreta adaptación protagonizada por Anthony Quinn. 


\section{perifèria}

Número 5, Diciembre 2006

www. periferia. name

Oscar Lewis había llegado a México en 1941 para llevar a cabo una investigación sobre el terreno en el pueblo que llamaría Azteca (en realidad Tepotzlan, una comunidad campesina de Morelos cercana a la capital). En 1951 se trasladó al DF, acompañando a sus antiguos informantes que emigraban del campo a la ciudad. De este modo conoció las vecindades que poblaban el centro histórico, donde residía una gran parte de los recién llegados. Las vecindades son viviendas típicas de la ciudad de México, herederas de las corralas coloniales, las cuales se caracterizan por alojar un número muy elevado de familias en habitaciones contiguas, a menudo muy pequeñas, situadas en torno a un patio central común y unos pasillos donde se sitúan los servicios comunes. Una puerta que se cierra de noche acostumbra a darle acceso, desarrollándose una intensa vida interna que tiene su expresión en las pandillas infantiles y juveniles (las palomillas) y en la ayuda mutua. Fue en una de estas vecindades, llamada Buena Vista, donde Lewis conoció a los Sánchez, en octubre de 1956. La familia estaba compuesta por el padre, Jesús, y sus cuatro hijos (Manuel, Roberto, Consuelo y Marta). Jesús Sánchez vivía en Buena Vista desde hacía ya más de 20 años. Su mujer había muerto de forma prematura y él había tenido que cargar con los hijos, con la ayuda de su cuñada, Leonor, quien residía en la Magnolia, una vecindad más pequeña sita a pocas cuadras de distancia. Incluso casados, los hijos iban a menudo a Bella Vista a visitar a su padre, aprovechando para dar un paseo por los múltiples talleres, baños públicos, cines, cantinas y pulquerías que había alrededor. A partir del estudio sobre el "pequeño mundo" de las vecindades, el antropólogo construyó su famosa teoría sobre la cultura de la pobreza. ${ }^{15}$

Para Lewis, los habitantes de las vecindades, originarios de casi todos los estados del país, compartían una serie de rasgos culturales comunes, resultado de la adaptación de tradiciones étnicas y regionales diversas al nuevo contexto urbano y a los problemas de la supervivencia diaria. El concepto de "cultura de la pobreza" no es pues una hipótesis fundada en la autobiografía de una única familia, sino que se originó en el estudio de 171 familias de dos vecindades y se amplió con

\footnotetext{
${ }^{15}$ Aunque muchas vecindades quedaron afectadas por el terremoto de 1985, aún hoy en día pueden visitarse en el barrio de Tepito, a diez minutos andando del zocalo (Lewis 1986).
} 


\section{perifèria}

Número 5, Diciembre 2006

\section{www.periferia.name}

posterioridad a otros ámbitos geográficos (Puerto Rico y los Estados Unidos). Con esta noción Lewis pretendía subrayar la lógica interna de una "adaptación cultural" que no podía ser definida exclusivamente en términos negativos: el autor indicó cerca de setenta rasgos distintivos de la cultura de la pobreza, agrupándolos en cuatro niveles que van desde la sociedad al individuo, pasando por la familia y el barrio. Uno de los primeros frutos de la investigación fue el libro Antropología de la pobreza, donde repasaba la vida diaria de cinco familias mexicanas durante cinco días ordinarios. Una de estas familias eran los Sánchez. Su disponibilidad le convenció que podía ser interesante dar una visión más profunda de una de estas familias, para probar en un estudio de caso sus teorías sobre la cultura de la pobreza. Pero hubo otra razón más práctica que hizo posible el estudio: la difusión de la grabadora. Las biografías de Ishi y de los emigrantes polacos fueron elaboradas utilizando técnicas de transcripción indirecta, como la escritura autobiográfica o la anotación etnográfica. Aunque Edison había inventado la grabadora a principios de siglo, no estaba aún lo suficientemente difundida como para permitir grabar sistemáticamente conversaciones espontáneas con informantes. En este período tampoco hay una excesiva preocupación por el lenguaje oral: el contenido domina sobre la forma. Esto facilita la reelaboración por parte del investigador del testimonio directo de los protagonistas. Durante los años 50 , sin embargo, la grabadora se vuelve portátil y se populariza. Pero es sin duda la obra de Lewis la que prueba su virtualidad para recuperar el tono directo y espontáneo del lenguaje popular. Como reconoce el autor, la grabadora es particularmente apta para estudiar a los pobres, que tienen una cultura ágrafa y a menudo analfabeta. De modo que el método se identifica con el objeto (las historias de vida con la cultura de la pobreza). ${ }^{16}$

\footnotetext{
${ }^{16}$ No es éste un momento para referirnos al debate suscitado alrededor del concepto de "cultura de la pobreza". Naturalmente, la obra tiene también numerosas 'lagunas'. Desde el punto de vista metodológico, los procedimientos para pasar de lo oral a lo escrito son ambiguos: en la introducción no se explican las técnicas, ni como se ensamblaron las entrevistas. En el caso de Consuelo, el relato oral se mezcla con fragmentos autobiográficos escritos por la protagonista. Tampoco queda claro si la versión castellana recoge la transcripción literal de las entrevistas, o si es una traducción revisada del original inglés. Desde el punto de vista teórico, los Sánchez se adaptan con dificultad al arquetipo de cultura de la pobreza (el mismo padre consigue saltarse a menudo los límites impuestos por aquella, y lo que impide ascender socialmente a sus hijos no es tanto su "cultura" como las barreras estructurales). En
} 


\section{perifèria}

Número 5, Diciembre 2006

\section{www.periferia.name}

La aportación metodológica más relevante de Lewis es la llamada “autobiografía cruzada". Pues el relato no se centra en la vida de un único individuo, sino en la historia de una familia. El mismo montaje del material autobiográfico resalta esta opción: después de una introducción del autor, donde se explicitan los antecedentes de la investigación, el contexto geográfico, histórico y social de los protagonistas, la parte central del libro (más de 500 páginas) se compone de distintos monólogos del padre y los hijos, los cuales narran los mismos hechos y dialogan implícitamente entre ellos. El padre, Jesús, sólo habla en el prólogo y en el epílogo, con un tono entre directo y cínico (el cual, como ya hemos visto, motivó la denuncia de los defensores de la moral): empieza explicando que "no tuve infancia" y termina justificando haber luchado "día y noche para establecer mi hogar". Los cuatro hijos hablan en las tres partes centrales, cada una de las cuales evoca determinados pasajes en la vida familiar: la infancia (marcada por la muerte de la madre), la juventud (evocada por los conflictos con el padre) y la edad adulta (definida por los problemas de la inserción laboral y estabilidad conyugal). En todos estos pasajes no se evitan los aspectos conflictivos, pues cada cual narra a su manera los hechos más relevantes de la vida familiar, lo cual contribuye a crear la sensación que más que de monólogos, nos encontramos delante un retablo polifónico. Se trata de una estrategia narrativa que, según el autor, sirve para verificar la fiabilidad y complementariedad de las fuentes orales, y que con posterioridad sería imitada no siempre con igual fortuna. Tan interesante como el contenido del libro es la reacción social que suscitó en México, originando una gran campaña de prensa contra el americano colonizador y la denuncia de la Sociedad Mexicana de Geografía y Estadística. Por suerte, el Procurador General de la República consideró que no había base jurídica para la condena. ${ }^{17}$

poner énfasis sobre el sistema de normas y valores, Lewis tendía a desentenderse de la base económica y de la organización social, haciendo aparecer como "cultura" a algo que en realidad era una serie de mecanimos de defensa delante una situación objetiva visible.

17 Para justificar la sentencia absolutoria se hace referencia a un artículo de prensa en el que se dice: “No recuerdo si fue San Vicente de Paul el que dijo: 'Los pobres son odiosos, pero hay que amarlos'. Esto es cabalmente lo que ocuprre con los miembros de la familia Sánchez, los cinco son odiosos, odiososo por su miseria, sus riñas salvajes, su lujuria, sus trampas, sus holgazanería y su crueldad; pero al concluir el libro de Lewis terminamos amándolos" (Lewis 1971: 519). 


\section{perifèria}

Número 5, Diciembre 2006

www. periferia.name

\section{La historia de vida como novela}

“Esto que llamamos novela no es más que una forma de narrar, de organizar quizás, que tiene su relación más primigenia con el relato. La novela no es más que una variante del relato. De los relatos de los viejos griots, de los chamanes, de los sacerdotes y de los juglares" (Barnet 1970: 125-6).

En febrero de 1926 el periódico de La Habana El Mundo publicaba un breve intitulado "Rachel en el Hipódromo", donde el periodista comentaba una fotografía, en la que un señor de la alta sociedad cubana había sido retratado en el hipódromo acompañado por una fastuosa cabaretera: “Bienvenida a este tablado Arlequín que es nuestro oriental para la mujer más atractiva de nuestro teatro, la más bella que, como la remota ciudad de Persépolis, tiene para mí un atrayente nombre: misterio" (citado en Barnet 1979: 12). Rachel fue en efecto durante las primeras décadas de siglo la vedette del Alahambra, uno de los locales más rutilantes de la belle epoque habanera. Era la única hija de una mujer húngara y un aventurero alemán, que habían llegado a Cuba a fines del siglo XIX. El padre las había abandonado y Rachel tuvo que ganarse su jornal desde muy pequeña, gracias a sus dotes musicales y de baile. Cuatro décadas después, en 1970, el reconocido etnólogo y poeta Miguel Barnet, que acababa de publicar Biografía de un cimarrón, la conmovedora historia de vida de un antiguo esclavo fugitivo, se encontró con Rachel, ya retirada y vieja, pero rodeada por los recuerdos y los fantasmas de los tiempos gloriosos, cuando era uno de los personajes más envidiados de Cuba, recuerdos y fantasmas que aceptó compartir con el escritor. La canción de Rachel narra su historia. El relato, organizado en primera persona, comienza con una declaración de intenciones ("Yo no soy bruja, ni gitana, ni cartomántica, ni nada de eso") y termina con los dilemas de una vida abocada al recuerdo ("Una persona sin recuerdos es como un árbol sin hojas"). Entre estas dos frases, un centenar de páginas donde se narra el nacimiento, esplendor y decadencia de la belle epoque cubana, a través del prisma de una reina de la noche.

La aportación más novedosa del libro es la estrategia de montaje por la que opta el autor, basada en la yuxtaposición de fragmentos del relato autobiográfico -que constituyen el eje central de la narración-, con entrevistas a personas de su 


\section{perifèria}

Número 5, Diciembre 2006

www. periferia. name

entorno familiar y social, notas de prensa y letras de canciones, que ayudan a situar mejor a la protagonista dentro de un tiempo y un lugar. Así, la función de contrapunto que en Los hijos de Sánchez cumplían los relatos cruzados, aquí lo cumplen los discursos biográficos paralelos, los cuales en su conjunto componen un auténtico puzzle o collage de una trayectoria vital. Pero Barnet no se limita a construir un retablo de la vida cubana a principios de siglo, sino que teoriza sobre lo que Ilama la "novela testimonio" (un nuevo género literario, que a su entender debería situarse a caballo entre el relato etnográfico y la novela realista): “La novela-testimonio tiene que ser un documento a la manera de un fresco, reproduciendo o recreando esos hechos sociales que marcarán verdaderos hitos en la cultura del país". Y es que el autor asume plenamente la naturaleza creativa del relato, con la salvedad que a diferencia de la novela clásica, se basa en una experiencia real (pero... ¿acaso no son también las grandes novelas frescos realistas de la vida social?). Aun y estar manejada por algunas cuerdas de ficción, Rachel es un ser de carne y hueso, y su experiencia pone de manifiesto algunos momentos, hechos y sensibilidades que han marcado la vida de un país. Así como Flaubert dice "Madame Bovary soy yo", el autor de la novela testimonio debe proclamar: "Yo soy la época". En el caso de Rachel, se trata de la experiencia de la Cuba republicana, con su etiqueta social, formas de diversión, modernización cultural y crisis políticas. Pero lo más destacable de una historia de vida no se refiere al pasado, sino al presente ("Ias consecuencias de un fenómeno son más importantes que el fenómeno en sí, su presente es más importante que su pasado). De hecho, Barnet se aleja explícitamente de Lewis, cuyo libro considera demasiado basto y primario, aunque vindica el papel creativo del autor en la recreación de la historia de vida. "La imaginación literaria debe ir cogida del brazo de la imaginación sociológica" (Barnet 1979: 134-140). ${ }^{18}$

\footnotetext{
${ }^{18}$ Esta técnica contrapuntística la llama por Rashomon - por la película de Akira Kurosawa- y consiste en "mirar a través de un espejo cóncavo, con el propósito de que el públcio se identifique con el libro" (Barnet 1979: 137). El libro de Barnet fue transformado también en película.
} 


\section{perifèria}

Número 5, Diciembre 2006

www. periferia.name

\section{La historia de vida como película}

"Más que una novela, el resultado se parece al de una película: bien sea porque al componer el texto siempre me he preguntado qué informaciones me hubieran servido para visualizar lo que quería contar (reminiscencia del 'no explicar, mostrar' de James), o bien por encima de todo por la centralidad del montaje y la reducción al mínimo del narrador. Como en una película, no todo lo montado aparece en el mismo orden en que se filmó, ni se ha montado todo el material filmado. La ley del realismo documental debe compartir el espacio con la del relato" (Portelli 1985: 14-15).

El 17 de marzo de 1949 Luigi Trastulli, un joven trabajador de una fábrica de acero de Terni, una ciudad industrial de la Italia central, moría después de un enfrentamiento con la policía, a raíz de una protesta obrera contra la entrada del país en la Organización para el Tratado del Atlántico Norte. La manifestación, el enfrentamiento y la muerte del trabajador duraron menos de media hora, pero dejaron una profunda huella en la memoria colectiva de la ciudad. Tres décadas más tarde, Sandro Portelli, un profesor de literatura americana en la Universidad de Roma, vinculado a la investigación militante, que estaban preparando un libro sobre la historia oral de Terni, rescató los testimonios de aquellos que vivieron los hechos, partiendo de los ruidos y los silencios implícitos en múltiples historias de vida. Director del Circolo Bosio y de la revista I giorni cantati, su interés por las historias de vida no provenía de la academia sino de la literatura y el canto populares, vinculados a diversas iniciativas de intervención en la cultura del mundo popular y subalterno, que en Italia debe mucho a la particularidad histórica del Partido Comunista durante los años de posguerra. El autor era una de las figuras punteras de la renombrada escuela italiana de las fuentes orales, que se inscribe en la tradición de estudio de las culturas populares que se remonta a autores como Antonio Gramsci, Ernesto de Martino y Gianni Bosio, y que se caracteriza por la vindicación de la especificidad de las fuentes orales. ${ }^{19}$

19 En sus Quaderni del Carcere, Gramsci (1932-5) había reivindicado la dimensión política de las autobiografías: la publicación de los Quaderni desde fines de los 40 sirvió de acicate para la recuperación 


\section{perifèria}

Número 5, Diciembre 2006

\section{www.periferia.name}

En realidad su investigación sobre Terni empezó como una indagación etnomusicológica sobre el repertorio de algunos cantautores politizados, que se transformó por requerimiento de los propios informantes en una completa reconstrucción de la memoria oral de la ciudad. Esta atención privilegiada al lenguaje oral rezuma todo el libro, como testimonio de la necesaria correspondencia entre forma y función (por eso se subtitula: Historia y relato: Terni 1830-1985). Ya que, mientras que las biografías que hasta ahora hemos analizado se centran en una persona o en una familia (en un grupo primario), el libro de Portelli es la historia de vida de una ciudad entera (por eso se titula Biografia di una città). Por el libro desfilan 172 personajes - “narradores” prefiere llamarlos el autor: obreros metalúrgicos, costureras, empleados, amas de casa, campesinos, artesanos, militantes políticos, curas, tifosi, intelectuales, desocupados, comerciantes, "heavy metal kids", músicos, periodistas, dirigentes y funcionarios: las múltiples voces de una comunidad sujeta a grandes cambios, recogidas, transcritas, elaboradas, montadas y mezcladas entre ellas y con otros tipos de fuentes. Todas juntas narran la visión de la historia de Terni desde comienzos de la industrialización hasta el presente. Debido a que la memoria oral no se limita a los recuerdos de la experiencia vivida, sino que recupera las tradiciones trasmitidas de generación en generación en el seno de la familia y de la comunidad, el libro empieza con la llegada de los garibaldinos, en el primer tercio del siglo XIX, lo que muestra que la historia oral va mucho más allá de los recuerdos de la contemporaneidad. ${ }^{20}$

\footnotetext{
de la historia de las clases subalternas; De Martino (1961) había empezado a utilizar sistemáticamente el magnetófono en sus investigación sobre la cultura popular del sur de Italia en los años 50; Bosio (1963) hizo del "elogio del magnetófono" un fundamente para la renovación de los estudios sobre el mundo popular y subalterno, utilizando las fuentes orales como fuente de documentación de una cultura no escrita y como factor de concienciación de los derechos políticos y sociales de la clase obrera y del campesinado, ampliando después el enfoque a los "nuevos sujetos" como mujeres y jovenes (sobre la escuela italiana de historia oral, ver Portelli 1989b; Feixa 1987; Contini 1991).

${ }^{20}$ Otra representante de la escuela italiana de historia oral es Luisa Passerini (1984), conocida por su magnífica reconstrucción de la memoria oral del fascismo en Turín y por una biografia experimental de la generación del 68, en cuyo interior combina narración autobiográfica con historia oral (1988).
} 


\section{perifèria}

Número 5, Diciembre 2006

www. periferia.name

Sin duda la aportación más original del libro es el procedimiento para montar el material autobiográfico, inspirado como Barnet en las técnicas cinematográficas, pero desarrollado mucho más sistemáticamente. No es nada casual que muchos de los diez capítulos en lo que se agrupan testimonios estén encabezados por el título de una película: "Qué verde era mi valle" evoca la transformación de un pequeño pueblo campesino en una activa metrópolis industrial; "Apocalypse now" narra los episodios bélicos (de la participación en la guerra de España hasta la caída de Mussolini); "Staying alive" describe los últimos años, marcados por el desencanto político y la crisis de la industria pesada. Pero no se trata sólo de un recurso estilístico: la fascinante lectura del texto recuerda el visionado de un filme, con constantes flash-backs, elipsis, planos cortos y visiones panorámicas. Cada capítulo agrupa testimonios de distintos informantes, que parece como si estuvieran dialogando entre ellos, junto a noticias periodísticas y referencias históricas. Portelli se queda voluntariamente en un segundo plano: su voz se escucha, especialmente en un denso prólogo donde reflexiona sobre la "propiedad del lenguaje", a través de la crónica de cómo sus informantes "tomaron la palabra". A lo largo del texto sólo de forma extraordinaria introduce valoraciones, interpretaciones o bien aporta alguna información para contextualizar los hechos narrados, pero en general opta por hablar a través de otras voces. Igual que un director de cine, su responsabilidad se centra en la selección de actores principales o secundarios, en los planos seleccionados y en las escenas rechazadas, y en el montaje final. Como en una película, no todo aparece en el orden en que fue filmado, y a menudo se da la libertad al lector para deducir, comprender e imaginar desenlaces reales o previsibles. $^{21}$

\section{La historia de vida como intercambio oral ritualizado}

\footnotetext{
21 Franco Ferrarotti (1986), uno de los introductores del método biográfico en Italia, cita el libro de Portelli como una de las aplicaciónes más originales del uso de fuentes orales. Sobre las aportaciones de Ferrarrotti, véase su obra Storia e storie di vita (1981) y la entrevista al autor incluida en este mismo monográfico.
} 


\section{perifèria}

Número 5, Diciembre 2006

www. periferia. name

"Me acuerdo de muchas canciones, las tonadas y las palabras, pero no por completo. Las cantábamos en las bodas y en las reuniones familiares, como esta: ‘¡Ah qué feliz soy, me acabo de casar/ con mi prima querida’ (...) ¡Podría creerse que hablo de un tiempo... del diablo! Pero en realidad hablo de cosas vividas, no hay nada que decir" (Catani \& Mazé 1982: 55-62).

Una tarde de junio de 1971, el antropólogo franco-italiano Maurizio Catani visitó a la tía de un amigo suyo, Suzanne Mazé, en su jardín de Bessancourt, cerca de Paris. Su amigo Michel, un escultor que había sido testigo en su boda, le había hablado varias veces de la prodigiosa memoria de su tía, de su capacidad para fascinar al auditorio con el relato de su vida y las canciones e historias que lo acompañaban, como el "sermón en defensa de los artesanos" que le había escuchado contar hacía poco; sabía que Catani estaba interesado en los relatos orales y había trabajado en historias de campesinos portugueses, españoles de las Hurdes, emigrantes senegaleses y argelinos en París. Por ello le propuso llamar a su tía para visitarla con las respectivas familias. Por si acaso, llevó su magnetófono, y lo puso en marcha nada más escuchar la intención de Suzanne, sentada en su jardín, de empezar a cantar: aunque ella se dirigía a sus dos sobrinas pequeñas, permitió que Maurice y su mujer se sentaran sobre la yerba para escucharla y empezó el relato diciendo "Je me souviens..." (Me acuerdo). Lo que recordaba eran las canciones de la infancia, que empezó a tararear ante la mirada admirada de sus familiares e invitados. Cuando acabó de recitar la larga canción, Suzanne exclamó: “Me he acordado de esta canción verso a verso. Tiene 19 coplas y las aprendí cuando no tenía más que 12 años. Fue antes de marcharme de casa de mis padres. A los 12 años me fui para ganarme la vida a casa de la hermana de mi padre, en esta famosa Mayenne. Pues todo lo que sé lo aprendí antes de los 12 años". Y concluyó: “¡Puede creerse que hablo de un tiempo... del diablo! Pero en realidad son cosas vividas". Cosas vividas que parecen fluir espontáneamente, pero que en realidad responden a modelos formalizados tanto en la forma como en el contenido, como deja entrever el sermón en defensa de los artesanos que recita a continuación (una apología del trabajo artesanal a la que ella y su marido dedicaron su vida). 


\section{perifèria}

Número 5, Diciembre 2006

www. periferia. name

Suzanne había nacido en 1902 en Mayenne, un pueblo del oeste de Francia, en el seno de una humilde familia rural. A los 12 años, como entonces era costumbre, va a aprender el oficio de modista con su tía. Ello marcará una frontera en su identidad biográfica: si la cultura es lo que queda tras olvidarlo todo, todo lo importante que sabe Suzanne (canciones, saberes, emociones, valores) afirma haberlo aprendido antes de esa edad. A los 20 años abandona a su tía para casarse con René Mazé, un relojero artesano emigrado a Paris, donde se instalaran para vivir del taller al que se consagrarán el resto de su vida profesional. Gracias a su trabajo artesano pueden llevar una vida acomodada y educar a dos hijos, sin olvidar sus origenes rurales. En 1955 Suzanne y René compran un jardín en la periferia parisina, desde el que se divisa la torre Eiffel. Es una propiedad simbólica, pues como afirma Catani representa la voluntad de "convertirse en parisino sin dejar de ser horticultor". No es casual que el relato se inicie precisamente en ese jardín, una especie de metáfora de la vida de la protagonista, memoria de infancia y refugio de identidad: “El jardín es el lugar ritual de la enunciación: canciones y relato. Hace concretas las relaciones que tia Suzanne ha vivido en su vida. Estas estan inscritas en los $1000 \mathrm{~m} 2$ comprados tras más de veinte años de vida parisina. Si en su infancia trabajo para una anciana cuya propiedad era para ella un paraiso, su jardín actual es lo mismo. Por otra parte, los vegetales plantados recuerdan a una persona o a un lugar: así es como la continuidad se inscribe sobre el terreno tras estructurarse en forma de relato. El inicio de nuestras entrevistas que tuvo lugar en el jardín no es el simpre resultado de un encuentro ocasional con motivo de un fin de semana en el campo, sino la inserción en un espacio donde relato y ritual se unen" (1982:448).

Tras este primer encuentro, Catani propuso a Suzanne completar su relato: del 21 de junio al 21 de julio grabó otras 4 sesiones, en la trastienda de su tienda de Paris, en su casa y de nuevo en el jardín, que constituyen la base de su "historia de vida social". En los años siguientes (hasta 1979) llevaría a cabo otras 7 entrevistas de control (incluyendo un viaje a su región de origen), volviendo sobre los mismos pasajes y comentando los análisis, pero sin cambiar el fondo y la forma del relato original. Con todo ese material, Catani publicó en 1982 un libro que revolucionaría las formas de escritura autobiografica: Tante Suzanne. Además de la autoría 


\section{perifèria}

Número 5, Diciembre 2006

www. periferia.name

(compartida por Catani y Mazé), y del largo subtítulo ("Historia de vida social y del devenir de una mujer que fue modista en la Mayenne durante Primera Guerra Mundial, y después esposa de un relojero de Paris, madre de dos niños y propietaria de un jardín en la periferia, sin negar jamás sus origenes"), su originalidad consiste sobre todo en la opción por conservar la integralidad del relato, lo que responde a una concepción de la historia de vida como "intercambio oral ritualizado". Se trata de una interacción comunicativa en la que lo que se intercambia es oralidad (autorepresentación del Yo). A diferencia de otro tipo de entrevistas, ello se hace de una forma ceremonial, formalizada, que recuerda a la solemnidad del ritual. Como el mismo autor teorizará en un artículo posterior, se trata de una especie de seducción amorosa: "La historia de vida social es, sobre todo, el producto de un encuentro, es el resultado de una seducción mutua, una historia de amor. El relato se mueve en diferentes niveles, todos los cuales están continuamente presentes en el encuentro de dos personas y su entorno... Este intercambio es simbólico, y en ese sentido está ritualizado: el discurso tiene una intención de ofrecer y recibir, implicando aquello que en nuestra cultura se valora como el más preciado de nuestros bienes: uno mismo" (Catani 1994: 258).

Catani distingue la historia de vida social de otro tipo de aproximaciones biográficas, como los relatos de prácticas, las secuencias biográficas, las entrevistas biográficas, la reconstrucción biográfica (el montaje de las informaciones se debe al investigador), y la auto-bio-grafía (en la que la utilización de la escritura elimina la presencia del auditor y la ritualización de la transmisión). La historia de vida social, en cambio, es un "relato que comporta la comparación y valoración de acontecimientos a cargo de un narrador que se asume como tal en función de valores, caso de Tante Suzanne". Bajo esta perspectiva, hay cinco rasgos que caracterizan a la historia de vida social: la autoconciencia del narrador a partir de una experiencia que juzga capital y permite la asunción de un 'yo'; la transmisión ritualizada del relato; la conducción del relato por parte del narrador; la introducción con una autorepresentación que da las líneas directrices de lo que vendrá después; su coralidad (además del narrador, participan su marido, ascendientes y descendientes y amigos. De ello se deriva una consecuencia metodológica clave: "Las entrevistas deben transcribirse y publicarse en su 


\section{perifèria}

Número 5, Diciembre 2006

www. periferia.name

integridad, incluyendo las intervenciones del oyente, porque debe ser posible seguir la emergencia del pensamiento del narrador junto con las preguntas. El oyente debe indicar el contexto de la recolección y el narrador debe poder dominar su texto llevando a cabo los cortes y añadidos que le parezcan oportunos. Finalmente, las entrevistas de control permiten a ambos precisar el contenido del análisis, que debe separarse netamente de la narración" (Catani \& Mazé 1982: 26, 30, 31).

Tante Suzanne constituye una fascinante ilustración de este diseño metodológico. Tras una introducción metodológica, la parte central del libro (uns 300 páginas) está dedicada a la "historia de vida social de Tante Suzanne", incluyendo la transcripción íntegra de las 5 entrevistas originales ("Un sermón en defensa de los artesanos", "Era muy orgullosa", "Tante Suzanne peina su primera casada", "EI exodo del "40", y "No sé qué más contaros"), solapadas cuando es preciso con añadidos fruto de las entrevistas de control posteriores. Cada una de ellas va precedida de una breve introducción con el contexto y le sigue un completo análisis de contenido, que incluye consideraciones sobre la estructura del relato y los valores que con él se comunican. El tema de los valores es clave: discípulo de Louis Dumont y con influencias de Lévi Strauss, Catani está interesado en las estructuras profundas, de naturaleza simbólica, subyacentes a las formas del relato oral. Por ello prioriza su dimensión ideográfica por encima de su potencial heurístico: las historias de vida no son relatos de prácticas (como piensa Bertaux) sino relatos míticos (aunque pongan de manifiesto algo tan real como es la identidad personal). Con anterioridad el autor había recogido relatos de distintos sujetos: un campesino portugués que le cuenta muchas cosas pero que no es capaz de contarle una historia; una mujer de las Hurdes que narra su vida pero no consigue razonar sus valores; un peul senegalés en Paris que enmascara su historia personal en la historia de su cultura; un joven argelino en Francia que narra su vida solitaria valorandola sólo de manera fragmentaria. Pero ninguno de ellos había sido capaz de autopresentarse como un Yo con la fuerza con que lo hacía Suzanne, lo que Catani ponía en relación con la emergencia de un nuevo tipo de subjetividad en Occidente (congruente con las teorías de Dumont sobre el individualismo como eje de la modernidad), paradójicamente representada en el relato de una humilde modista. La de Catani-Mazé es sin duda una apuesta tan fascinante como dificil: la 


\section{perifèria}

Número 5, Diciembre 2006

www.periferia. name

prueba es que el autor no ha tenido seguidores y el libro ha quedado como un camino abierto pero sin solución de continuidad. ${ }^{22}$

\section{La historia de vida como hagiografía contracultural}

“Ayer, en Gracia, por la noche, a las siete; en una plaza, allí bebiendo en un bar, con un amigo mío. Y tenía un petardo y digo: "Me voy a la calle a liarlo", porque el tío del bar ya me había dao la bronca anteriormente por liar pertardos en el bar; y pensé: pues me voy a la calle. Y como había unos chavales fumando, pues les pedí papel de fumar - yo tenía- y les pedí un cigarro rubio, a pesar de que también tenía... me lié un petardo y empecé a hablar con ellos... niños ¿no?, jovencitos, de esos de la nueva ola, de esos chavales que fuman grifa sin saber lo que hacen" (Romaní 1983: 151).

A finales de 1981 un personaje fascinante conocido con el apodo de el Botas, exlegionario, exgrifota, exjipi, extraficante, expresidiario, de vuelta de todo, decide contarle su vida al antropólogo Oriol Romaní, empezando por sus orígenes en el barrio chino barcelonés (con un padre anarquista y una madre de origen rural) y acabando por sus contactos con los jóvenes de la nueva ola en un bareto del Raval (el ecosistema urbano parece salir directamente de los comics de Ivà). Romaní le había conocido mientras preparaba su tesis doctoral sobre la historia cultural del hachís en Barcelona, un tema en aquel momento extraordinariamente novedoso para la antropología española. Fue Joan Prat quien le sugirió que investigara el tema, dado que lo conocía de primera mano al haber participado en la movida alternativa de la ciudad. Como para reconstruir la historia de una práctica clandestina como el consumo de marihuana a penas existían fuentes escritas (más allá de algun informe policial inaccesible y de la propia prensa contracultural), las fuentes orales se conviertieron enseguida en el método natural para sumergirse en el mundo de la contracultura autóctona. El autor no tuvo problemas en encontrar informantes de su propia generación que quisieran compartir con él su historia -en

\footnotetext{
${ }^{22}$ Catani ha realizado también estudios sobre la inmigración africana en Francia (en 1973 publicó Journal de Mohamed, que relata la vida de un joven argelino en Paris) y sobre las Hurdes (1997).
} 


\section{perifèria}

Número 5, Diciembre 2006

www. periferia.name

realidad, la suya propia; en cambio, le fue mucho más dificil acceder a la generación anterior, la que había vivido la prehistoria del "rollo". Por ello optó por buscar la mediación de algunas instituciones de asistencia y reinserción social con las que había colaborado. Fue así como llegó al Botas. El personaje no sólo no puso ningún impedimento para contar su vida, sinó que se convirtió en orgulloso cómplice de la obra: durante el último trimestre de 1981, en un lapso fuera de chirona, dedico dos o tres veces por semana a hablar con el antropólogo, que iba transcribiendo cuidadosamente el relato. Cuando el autor leyó su tesis, en 1982, algunos miembros del tribunal le hicieron saber que la historia del Botas, que ocupaba uno de los apéndides, era de los más interesante, y por ello no descansó hasta publicarla, con un título impactante: A tumba abierta. Autobiografía de un grifota (1983). ${ }^{23}$

El libro de Romaní no es la primera autobiografía antropológica realizada en España. El mismo autor se reconoce en el prólogo continuador de diversas obras que, desde los años 60, habían intentado recuperar el testimonio de distintos tipos de sujetos, por lo general marginados (emigrantes, rebeldes, campesinos, ladrones). Lo novedosos de su aportación, además de la riqueza narrativa del relato, fue sobretodo el impacto social de la obra. A tumba abierta se convirtió en un libro de referencia (y de paso en un éxito de ventas). Pudo influir que no se publicara en una colección académica, sino en la serie literaria de Anagrama (Contraseñas) donde se habían publicado también - por ejemplo- los libros de Charles Bukowski (el impactante dibujo de portada, un cómic de Julio Vivas que retrataba al Botas tatuado fumando tranquilamente grifa, sin duda fue también una buena promoción). Se vendieron dos ediciones y se tradujo al portugués (con el titulo de A peito aberto). Ignoro si es el libro más vendido de la antropología española, pero sin duda debe ser el más leído: las ediciones pasaban de mano en

23 El libro hace tiempo que está fuera de catálogo y en algunas bibliotecas universitarias ha desaparecido. Por ello me gustaría aprovechar para pedir su reedición ahora que la contracultura y los 60 vuelven a estar de moda. 


\section{perifèria}

Número 5, Diciembre 2006

\section{www.periferia.name}

mano entre el círculo de amigos y enterados, y cuando se agotó empezó a circular en fotocopias, en librerías de viejo y en el mercado de segunda mano. ${ }^{24}$

El relato está condensado en 150 páginas y ordenado de manera cronológica en cinco capítulos que narran, respectivamente, la infancia y juventud en la Barcelona de posguerra, la legión en África, los trapicheos en la Barcelona de los 60, la inmersión en el movimiento "jipi" en Suecia y Holanda, y finalmente el retorno a la Barcelona posfranquista. Aunque se trata de un monólogo, el tono oral del relato dejan entrever la decisiva intervención del antropólogo y lo distinguen de otros discursos más intelectualizados sobre la contracultura. En un breve prólogo, Romaní contextualiza las coordenadas teóricas y metodológicas del relato. Lo peculiar de la historia es la conexión que se establece entre el modelo del grifota y el del jipi. El tema de la tesis era precisamente la evolución de un modelo "tradicional" a uno "moderno" en el consumo de drogas, lo que la trayectoria del Botas reflejaba perfectamente: de origen popular, su estancia en la legión le permitió introducirse en el consumo de grifa, convirtiéndolo en modus vivendi al retorno a Barcelona; fue como pequeño traficante que entró en contacto con los 'jipis', jóvenes de clase media que empezaban a construir una contracultura autóctona (que pese a inspirarse en un modelo internacional, siguió caminos propios). Su matrimonio con una jipi sueca le permitió conocer de primera mano las mecas de la contracultura europea: Amsterdam, Copenhague, Estocolmo. Y su retorno a Barcelona, en plena transición, le volvió a poner en contacto con una subcultura de la droga que la introducción de heroína había transformado profundamente. ${ }^{25}$

\footnotetext{
${ }^{24}$ Antes de la obra de Romaní, deben citarse Hacer la América. Biografía de un emigrante de Marsal (1972), Testimonio de un rebelde de Maestre Alfonso (1976), Biografía de un campesino andaluz de Jimeno (1978), y en el ámbito no académico, Camina o revienta de Eleuterio Sanchez, el Lute (1979). Después de la publicación de A tumba abierta, han sido multitud los antropólogos españoles que han utilizado las fuentes orales en sus investigaciones, aunque en la mayoría de las ocasiones se trata de usos parciales e ilustrativos, no de relatos completos. Vale la pena destacar, en este sentido, diversas monografías sobre drogas (Romaní \& Funes 1985; Gamella 1990), mujeres (Comas et al. 1990), sectas (Prat 1998), sexualidad (Vendrell 1999), niños de la guerra (Devillard et al. 2001), entre muchas otras contribuciones.

25 “Su historia no sólo era interesante porque se encontraban concentrados en una sola persona muchos de los principales temas que formaban el objeto de mi investigación, sino porque, primero a través de la relación que establecí con él, y después una vez ya terminada la biografía, me pareció claro que se
} 


\section{perifèria}

Número 5, Diciembre 2006

\section{www.periferia.name}

A tumba abierta retoma la tradición autobiográfica de la escuela de Chicago (en particular, The Jack Roller de Shaw), en su interés por los tipos marginales y por las zonas liminares de la cultura urbana. Pero en su escritura textual está mucho más cerca de Los hijos de Sánchez, por su respeto del origen oral del testimonio y su enorme calidad literaria. Sin embargo, su originalidad estriba sobretodo en la influencia de un tercer tipo de discurso autobiográfico: la literatura contracultural. Contramodelo de las vidas de santos (hagio-grafías) que durante mucho tiempo han constituido la tradición central de la escritura autobiográfica en Occidente, la aportación de Romaní se inscribe en un género de vidas de héroes contraculturales (o contra-hagiografías) que conforman modelos de subjetividad y socialidad alternativos. La literatura contracultural tendió a buscar modelos de vida alternativos pero plausibles, vagamente literarios, que describen casi siempre viajes iniciáticos, como muestran las novelas de Kerouak, Hesse y Castaneda (pero también los ensayos de Reich, Marcuse y Racionero). Pese a ser ejemplos a no imitar (el joven descarriado, el chico malo, el perdedor) suscitan la fascinación de lo rebelde, que en una época de crisis de las ideologías eran para muchos jóvenes del posfranquismo (y para viejos rockeros que nunca mueren) una especie de paradigma de lo que pudo ser y no fue. El mismo Romaní reconoce que la inspiración para su estudio le vino de la lectura de unos artículos con el título general de "Nosotros los malditos" que se publicaron el la revista contracultural Star en 1977. Los malditos no son ya, pues, marginados que asumen su condición

trataba de una historia muy atractiva, tanto por la gran cantidad y tipo de experiencias que contaba muchas veces tienen la emoción de un sólido relato de aventuras vividas-, como por la manera de contarlo. Un lenguaje con imágenes muy plásticas y un mordaz distanciamiento irónico de las cosas que le llevan a reirse de su misma sombra hasta en los momentos más trágicos y duros de su existencia -y ha sido o, mejor dicho, es la suya una existencia muy dura- le dan a toda su historia un frescor que estoy seguro que el lector sabrá apreciar" (Romaní 1983: 10). En un texto posterior, el autor reflexionó sobre las relaciones entre informante e investigador en la construcción de historias de vida. Frente a los planteamientos más naturalistas, optaba por una perspectiva más empática, "pues lo que nos interesa a los antropólogos, además de unos hechos coailes externos, son otro tipo de 'hechos sociales', como las para' cticas sociales de individuos concretos, las valoraciones de la vida que expresan, las vivencias y sensaciones que conforman su cotidianidad" (Romaní 1984: 5-6). 


\section{perifèria}

Número 5, Diciembre 2006

www. periferia.name

"anómica", sino nuevos héroes urbanos que convierten su estigma en emblema, su historia de vida en hagiografía contracultural. ${ }^{26}$

\section{La historia de vida como antibiografía}

“La antibiografía no escribe la vida de una persona pero nos habla de ella. Nos habla de aquello que se hace contra su vida, a su alrededor y sin contar con su vida. La antibiografía es un conjunto de producciones culturales y actitudes sociales que convierte en personajes y en símbolos o emblemas a las personas que se tienen como insignificantes, a las personas cuya biografía no vale la pena escribir porque no puede considerarse original o significativa" (Terradas 1992: 13).

El 31 de agosto de 1844, un periódico inglés vinculado al movimiento cartista daba noticia sobre la muerte de Eliza Kendall, una joven trabajadora inglesa que se había suicidado arrojándose al Long Surrey Canal. El suceso fue suficientemente significativo como para que Friedrich Engels lo nombrara en una nota al pie de su libro más conocido - La situación de la clase obrera en Inglaterra (1845). En esta obra, resultado de una larga observación "en el terreno" en el Manchester fabril, Engels dedica un capítulo a las otras ramas industriales- incluyendo las industrias a domicilio-, donde había una referencia a la joven cosedora suicida, tomada como emblema de la alienación capitalista, de la extrema explotación que el sistema del putting out imponía a los trabajadores, en particular a mujeres jóvenes de la clase obrera, y en el que se basaba el esplendor burgués. Un siglo y medio después, Ignasi Terradas aprovechó el caso para construir uno de los retablos más sugerentes -y desgraciadamente más ignorados- de la historiografía catalana reciente. El trabajo de Terradas empieza precisamente allá donde termina el de Engels: recuperando los perfiles de la noticia de prensa, el autor invierte los vínculos del discurso biográfico: la teoría marxista pasa a ser una nota al pie en la vida de Eliza, que en su marginalidad asume un papel central en la comprensión del

\footnotetext{
${ }^{26}$ El final de la vida del Botas también fue trágico y relacionado con nuevos estilos juveniles: unos skinheads le dieron una paliza quedando ciego; acabó vendiendo cupones de la ONCE hasta que murió a fines de los 90 .
} 


\section{perifèria}

Número 5, Diciembre 2006

www. periferia.name

funcionamiento cultural del capitalismo industrial. Repasando la documentación periodística -concretamente la sección de hechos diversos del periódico cartista- el autor reconstruye los perfiles de un caso paradigmático. ${ }^{27}$

Eliza Kendall era la segunda de cuatro hermanas, huérfanas de madre, que vivían con su padre en una casita de una zona portuaria cercana a Londres. Las cosas no les iban bien: el padre se había quedado sin trabajo y tenían que mantenerse con el escaso salario que las dos hermanas mayores ganaban cosiendo camisas a domicilio. Además, debían devolver con intereses el coste de los materiales que los capitalistas les avanzaban, bajo la amenaza del embargo. Cuando Eliza tenía 18 años, decidió poner fin a su vida sumergiéndose en las aguas del canal. En el proceso posterior, el jurado denunciaría “la práctica cruel de los traficantes de ropa basta de Londres de ocupar a jóvenes cosedoras con unos salarios tan bajos que imposibilitan la misma subsistencia". Terradas no se limita, empero, a las breves referencias periodísticas que determinan la vida y la muerte de una persona insignificante, sino que explora en los vacíos de información y en los silencios de la historia oficial para poner en evidencia las luces y las sombras de un tiempo y de una situación social. Es lo que él Ilama "antibiografía". Ésta se define como "la parte de vacío o negación biográfica susceptible de revelarnos aspectos importantes del trato que una civilización tiene con las personas concretas" (Terradas 1992: 13). El autor analiza distintas variantes contemporáneas de este género: la antibiografia periodística del cartismo, la económica del marginalismo, la romántica de Goethe, la crítica de Marx, la poética de Leopardi. De forma que la insignificante historia de Eliza, se relaciona con el primitivo movimiento obrero, con el auge del trabajo a domicilio, y con las heroínas de la tragedia y la lírica románticas. Eso que poseen las personas marginadas (en razón con su género, edad y condición social) es la medida del valor que una civilización atribuye a sus miembros. Los silencios, vacíos y el caos que proyecta sobre sus vidas, convirtiéndolas en convencionalmente

\footnotetext{
${ }^{27}$ La referencia de Engels a Eliza Kendall es anónima. El pasaje (que en la edición castellana aparece dentro del texto) dice concretamente: "las obreras deben reponer, en parte, el importe de los materiales a ellas confiados, lo que no es posible esto lo saben también los propietarios- más que empeñando una parte de ellos y rescatándola con pérdida, o si no lo logran, compareciendo ante el tribunal de paz, como le sucedió a una modista en noviembre de 1843. Una pobre muchacha que se encontraba en este caso y no sabía qué hacer, en agosto de 1844 se ahogó en un canal" (Engels 1979: 197).
} 


\section{perifèria}

Número 5, Diciembre 2006

www. periferia.name

insignificantes, ponen de manifiesto, en un sentido inverso, todo aquello que esta civilización ha tenido que hacer para conseguir esta reductibilidad. Este reverso aparece precisamente en las vidas menos visibles, y sin embargo más significativas en su imposibilidad biográfica, es decir, en su imposibilidad de escribirse y encontrar un hilo argumental, en su antibiografía. De este modo, no son las personas reales las que aparecen como una nota al pie para documentar un determinado sistema socioeconómico, sino que es este sistema el que aparece como una nota al pie para iluminar la vida de una persona de carne y huesos. De modo que lo marginal para al centro, y lo central a los márgenes. ${ }^{28}$

\section{La historia de vida como dialógica}

“He pensado que esta presencia implícita mía es importante y refleja la interacción mutua que se dio entre los dos" (Frigolé 1996: 23).

“Las páginas que siguen hablan de Sebastià Piera, de su vida completa, tal y como él me la explicó y tal como yo, posteriormente, se la he explicado a él" (Vinyes 1998: 10).

El 18 de julio de 1936 un socialista murciano ya maduro, Juan de P., y un joven comunista catalán, Sebastià Piera, salieron de sus casas para defender la II República, sin ser conscientes que esta decisión les acarrearía, en un futuro más o menos próximo, la represión, la tortura, y la cárcel. Muchos años después, ambos entraron en contacto con sendos investigadores que escucharon su relato y lo convirtieron en escritura biográfica. Un hombre es el relato de un trabajador agrícola murciano, que el antropólogo Joan Frigolé recogió durante el trabajo de campo que llevó a cabo a principios de los años 70, y que ha elaborado y enriquecido con un denso aparato crítico. Juan de P. nació en la Murcia rural en 1901, en el seno de una familia de arrendatarios pobres. La infancia y primeriza iniciación laboral, el noviazgo y el matrimonio, el compromiso político durante la II República, la participación en la guerra, la experiencia de las cárceles y la represión

\footnotetext{
28 Terradas se refiere a la crítica de Pierre Bourdieu en su conocido artículo "La ilusión biográfica" (1989), y a la réplica de Yves Clot "La otra ilusión biográfica" (1989).
} 


\section{perifèria}

Número 5, Diciembre 2006

\section{www.periferia.name}

franquistas en la posguerra, la reinserción en la vida laboral y los conflictos con los amos, la emigración de sus hijos, constituyen los momentos clave de su itinerario vital, verdadero microcosmos donde se ven reflejadas las transformaciones del campesinado español a lo largo del siglo XX. ${ }^{29}$

El soldat de Pandora es la biografía de un revolucionario catalán del siglo XX, que el historiador Ricard Vinyes ha elaborado a partir de una serie de entrevistas realizadas al protagonista y de una búsqueda documental complementaria. Sebastià Piera nació en Baldomà (en la comarca catalana de la Noguera) en 1917, en el seno de una familia republicana ilustrada. I gual que muchos jóvenes de su generación, vivió la proclamación de la II República con una gran esperanza. Con el estallido de la guerra, no dudó en alistarse como soldado y empezó a militar en el Partit Socialista Unificat de Catalunya (PSUC). Con la derrota inició una epopeya que lo llevó desde los campos de concentración de la Cataluña Norte a Córcega, pasando por el Báltico, Moscú, Ucrania, el Cáucaso, Lituania, Rumania, Italia, Francia y un retorno fugaz a Cataluña. Su activa participación en el frente soviético durante la II Guerra Mundial, la dispersión familiar, su detención y tortura a manos de la policía franquista en 1947, el retorno al exilio, los problemas con el partido, el confinamiento en Córcega, la lucha contra el secuestro de su hijo por el estado francés, la difícil reubicación familiar y profesional, constituyen episodios de una vida singular, no tanto por los hechos que protagonizó, sino por el significado moral de los actos en que se comprometió.

\footnotetext{
${ }^{29}$ Los libros tuvieron notable repercusión en la prensa, avanzándose al fenómeno de recuperación de la memoria del franquismo (con 25 años de retraso a la muerte del dictador). Sobre Un hombre aparecieron varias reseñas. José M. Guelbenzu, por ejemplo, escribió un emocionado comentario en EI País (8-2-99): "Hay libros cuya pérdida es un dolor y más que un dolor: un síntoma de debilidad de espíritu (...) El libro es impresionante, es como volver a tocar el nervio central del país al que pertenecemos. En el cambio que se está produciendo en España desde hace un par de decenios está faltando, sobre todo, la referencia y el contraste con el pasado inmediato y las características culturales propias". María Cátedra comentó en la Revista de Libros (1999: 27): "Un hombre es a la vez un interesante testimonio histórico y un fascinante documento humano. A lo largo de sus páginas se aprecia el desarrollo de una persona y su lucha por la superviviencia y la dignidad (...) con este relato, Juan ha entrado en la historia". El soldat de Pandora permaneció durante varias semanas en la lista de libros más vendidos en catalán. Con posterioridad, el autor se ha dedicado al estudio de las cárceles franquistas, a partir de un impresionante reportaje televisivo, basado también en entrevistas a mujeres encarceladas a quienes robaron sus hijos, convertido después en libro: Els nens perduts del franquisme (VV.AA. 2002).
} 


\section{perifèria}

Número 5, Diciembre 2006

www. periferia. name

Más que la condición social de los actores, aquello que une ambas biografías es, por encima de todo, el fundamento ético de su compromiso político. Mientras Frigolé (1997: 14-5). subraya que el relato de Juan "es una respuesta moral y política a los peligros que acechan a la supervivencia física, social y moral de él y de los suyos", Vinyes (1998: 11) recuerda que Piera "resultaba histórico en sentido moral, es decir, por los actos, no por los hechos; era su actitud frente al contexto histórico, no su protagonismo en el desarrollo de un contexto en el que interesaba a mi propósito". A pesar de las coincidencias de las historias de vida y del método utilizado para construirlas (basado en un alto grado de confianza entre el observador y el observado, y en una búsqueda complementaria para poner de relieve el contexto histórico y cultural de la biografía), ambos autores utilizan formas de escritura autobiográfica distintas. Frigolé opta por una narración en gran medida lineal, cuyo eje articulador es el relato oral del protagonista, que transcribe con gran fidelidad y precisión, por lo que respeta tanto las formas verbales como los contenidos (con particular atención al lenguaje dialectal). En cada uno de los capítulos los hechos se ordenan según van sucediendo, aunque no siempre coincidan con el orden de la entrevista oral. Frigolé asume plenamente su coautoría, sin renunciar a intervenir en la reelaboración del texto si acaece, ya que lo importante es ser fiel a la persona que habla, más que a la cinta en la que se va a registrar su voz: "es un orden construido, impuesto a sus recuerdos, adoptando un criterio parecido al del orden vital". El resultado final refuerza la impresión de una narración naturalista muy cercana a los hechos. Lo más original no es tanto el tratamiento otorgado a las fuentes orales como la opción de utilizar las notas al pie de página para documentar el contexto histórico y etnográfico del relato, refiriéndose a otros materiales procedentes del trabajo de campo (fragmentos del diario de campo, entrevistas a otros informantes, fuentes bibliográficas y documentales complementarias, etc.). Una densa introducción en la que se explicitan las condiciones de la investigación y se presentan los grandes referentes temporales y culturales de la biografía, aportan numerosos instrumentos para situar la historia de vida en la historia social. 


\section{perifèria}

Número 5, Diciembre 2006

www. periferia.name

La estrategia narrativa de Vinyes es bastante diferente: la oralidad queda sumergida en la escritura, ya que opta por reelaborar de forma literaria el contenido de las conversaciones que durante cuatro años mantuvo con su informante. Los veinte capítulos en los que se agrupan las 200 páginas del relato no están ordenados sólo bajo una perspectiva cronológica, sino que la narración (con constantes flash-backs, saltos hacia delante y hacia atrás y asociaciones metafóricas), se basa en "el desplazamiento del pasado a través del instrumento histórico y cognitivo que es la memoria, la cual opera de forma discontinua, con asociaciones rápidas, aparentemente desordenadas pero significativas". De hecho, el narrador es múltiple: el relato de Piera constituye el eje vertebrador, pero se combina con miradas complementarias sobre su vida: los testimonios de una compañera rusa de la guerrilla y de su mujer, la sentencia de su juicio, las fotografías y noticias de prensa que ilustran su itinerario, y sobretodo las interpretaciones que Vinyes va apuntando a lo largo del texto. El texto no se separa de su contexto (que no aparece a pie de página, sino que va emergiendo a lo largo del relato, a través de la descripción poética de paisajes físicos y morales): “El historiador no se fundamenta en la fábula, pero sin embargo organiza los elementos reales y utiliza -conscientemente $\mathrm{o}$ no- procedimientos retóricos destinados a producir efectos de realidad, a mostrar que aunque nosotros no estábamos allí, las cosas, fueron, efectivamente, como lo estamos narrando" (1998: 13-14). La publicación de estas obras ha servido para incitar un necesario debate sobre la renovación de la imaginación autobiográfica. No es casual que ello haya sucedido en un momentos en que se vuelve la mirada al gran suceso de la historia nacional que hasta ahora había permanecido silenciado: la guerra civil. No sólo por la censura oficial del franquismo sino porque la transición tendió a equiparar amnistía con amnesia. ${ }^{30}$

\footnotetext{
${ }^{30}$ En octubre de 2002 tuvo lugar en Barcelona un congreso sobre las cárceles franquistas, en el que presenté junto con la historiadora Carme Agustí una ponencia sobre "Los discursos autobiográficos de la prisión política", centrada en la relación entre amnistía y amnesia (memoria y desmemoria) de la guerra civil y del franquismo (Feixa \& Agustí 2003), El congreso tuvo un gran impacto social y mediático, despertando la pasión autobiográfica por un periodo silenciado (la apertura de fosas comunes de fusilados de la guerra, promovidas por la Asociación para la Recuperación de la Memoria Histórica, es otra cara del mismo fenómeno).
} 


\section{perifèria}

Número 5, Diciembre 2006

www. periferia. name

\section{Epílogo}

“Es cierto que la autobiografía tiene un gran valor histórico, ya que muestra la vida en acto y no sólo como tendría que ser según las leyes escritas o los principios morales dominantes (...) Sin embargo la historia, en líneas generales, se hace sobre la ley escrita: cuando nacen después nuevos hechos que invierten la situación, surgen preguntas vanas, o falta documentar cómo se ha preparado 'molecularmente' la mutación antes de explotar" (Gramsci 1975: 1718-24).

Estas reflexiones de Antonio Gramsci, redactadas entre 1932 y 1935, forman parte de un fragmento titulado "Justificación de las autobiografías", incluido dentro de uno de los cuadernos que redactó durante su estancia en las cárceles mussolinianas. La cárcel es uno de los territorios autobiográficos por antonomasia, pues desde ese espacio de reclusión la reflexión sobre el propio pasado y la propia identidad surgen espontáneamente y se comunican hacia el exterior mediante diferentes formas de escritura (carta, memoria, grafiti, tatuaje). El pensador italiano fue uno de los primeros autores marxistas que revindicaron el género biográfico como un instrumento fundamental en la investigación social. Analizando el uso limitado del género autobiográfico en la cultura italiana, lo ponía en relación con la endeblez de la cultura subalterna para hacerse oír y convertirse en hegemónica, impulsando un cambio de subjetividad. Sólo a través de las biografías se puede ver el "mecanismo" en acto, encarnado en individuos reales: la autobiografía se puede concebir "políticamente", porque aunque sea similar a muchas otras vidas, siempre contiene salidas originales. Historia y vida son polos complementarios en la construcción de un tipo de materialismo humanístico que tendría que permitir entender no sólo cómo funcionan las estructuras, sino también cómo reaccionan las personas concretas a los cambios históricos, o en palabras del autor, cómo estos cambios se preparan de forma invisible - "molecularmente"antes de estallar. El mismo Gramsci, en las cartas que escribió desde la cárcel a su mujer y a sus hijos, muestra la fecundidad de la escritura biográfica y el carácter dialógico de toda reflexión vital comporta. 


\section{perifèria}

Número 5, Diciembre 2006

www. periferia.name

Las historias de vida construidas dialógicamente por Ishi y Theodora Kroeber, por Helena Dawrowskis y Florian Znaniecki, por los oficiales nazis y Theodore Abel, por Jesús Sánchez y Oscar Lewis, por Rachel y Miguel Barnet, por Luigi Trastulli y Sandro Portelli, por Suzanne Mazé y Maurizio Catani, por el Botas y Oriol Romaní, por Eliza Kendall e Ignasi Terradas, por Juan de P. y Joan Frigolé, por Sebastià Piera y Ricard Vinyes, constituyen fecundos ejemplos de aquel "leer una sociedad a través de una biografía" que el sociólogo italiano Franco Ferrarotti (1981) propuso hace ya unos cuantos años. Pues aunque ninguno de estos personajes pueda considerarse, en sentido estricto, representativos de sus respectivas culturas, sus voces nos dan claves para comprender los sistemas sociales en los que sus vidas se insertan (a menudo mucho mejor que cualquier sesudo y frío tratado académico sobre la cuestión). Las propias formas de aparición y reconocimiento de los protagonistas, así como el carácter dialógico de la relación con los autores de las biografías y la representación de esta relación en la escritura, pueden tener, sin duda, un mayor potencial de desarrollo.

A lo largo del casi un siglo que separa el testimonio de Ishi y el de Suzanne, puede observarse un desplazamiento de los sujetos observados: al principio son casi siempre hombres ancianos o adultos, con un papel influyente en su comunidad pero marginal en la sociedad global; después empiezan a aparecer mujeres y jóvenes, con un protagonismo menos evidente pero una posición global mejor. También cambia la óptica de los investigadores: al principio la relación con los informantes (normalmente analfabetos) es muy desigual, lo que se traduce en una gran distancia; después la relación se hace más igualitaria y la "empatía" más evidente (entre otras cosas, porque los sujetos investigados, que en algunos casos pasan a ser coautores, empiezan a leer los libros resultantes). Lo mismo sucede con las formas de escritura autobiográfica: al principio predomina el discurso escrito mediatizado por documentos personales y por el investigador que reelabora lo hablado en términos literarios; después de la difusión del magnetófono, la oralidad toma un nuevo protagonismo y la obsesión por la literalidad se hace más presente. En los últimos años la introducción del video supone un replanteamiento de las técnicas de recogida y montaje, con una atención cada vez mayor a los aspectos visuales de la auto-representación biográfica. 


\section{perifèria}

Número 5, Diciembre 2006

www. periferia. name

Pese a la gran diversidad de circunstancias históricas, medios geográficos, disciplinas académicas, técnicas de entrevista, estrategias narrativas y formas de presentación textual, todas las historias de vida que hemos presentado tienen como común denominador haberse basado en diálogos (más o menos directos, más o menos igualitarios, más o menos sinceros, más o menos mediatizados) entre un informante que narra su vida y un investigador que pregunta, analiza y elabora lo hablado (entre un sujeto observador y un sujeto observado). Por lo que puede ser útil volver a mirar, con renovado espíritu dialógico, a los indígenas, inmigrantes, oficiales, pobres, artistas, comunistas, modistas, grifotas, obreras y militantes políticos cuyas palabras de vida hemos evocado fugazmente en este ensayo. ${ }^{31}$

\section{Bibliografía}

Abel, T. 1938. Why Hitler Came into Power, New York, Prentice Hall.

Abel, T. 1947. "The Nature and Use of Biograms", American Journal of Sociology, 53: $111-8$.

Anderson, N. 1923. The Hobo. The Sociology of the Homeless Man, Chicago, University of Chicago.

Bakhtin, M. 1981 (1994). The Dialogical Imagination, Austin, University of Texas Press.

Balán, J. (ed). 1974. Las historias de vida en ciencias sociales, Buenos Aires, Nueva Visión.

Balán, J. et al. 1974. "El uso de historias vitales en encuestas y su análisis mediante computadoras", in Balan (ed).

Barnet, M. 1965 (1980). Biografía de un cimarrón, Madrid, Siglo XXI.

\footnotetext{
${ }^{31}$ Como investigador, me he dedicado a experimentar con la imaginación autobiográfica con distintos sujetos sociales y variadas estrategias textuales: cinco generaciones juveniles en un relato polifónico a la Portelli (1990, 1992); tres viejos raiers -navegantes fluviales del Pirineo- en una crónica novelada a la Barnet (Iniesta, Villaro \& Feixa 1991); dos jóvenes punks de ambos lados del Atlántico en una reconstrucción contracultural a la Romaní (1998); cinco chavos y chavas indígenas, fresa y banda mexicanos en un relato cruzado a la Lewis (1998). También he recogido relatos inéditos de jóvenes lesbianas, estudiantes erasmus y distintas generaciones de mi propia familia originaria de una casa del Pirineo. Mi última experiencia ha sido con videohistorias de vida: gracias a un encargo del Museu de Vilafranca y la colaboración de Urano Films, he recogido el relato de 3 famílias inmigrantes (procedentes de Ecuador, Marruecos y Ucrania), focalizándolo en su cultura material, lo que se ha traducido en breves documentales proyectados en el museo y la televisión local: Allà des d'Aquí. 3 famílies, 3 orígens, 3 itineraris (Feixa \& Espinosa 2003). En la actualidad, me interrogo sobre cómo convertir en historia de vida el relato de dos jóvenes bien distintos: un lúcido punk mexicano cuya biografía empieza con su abuela soldadera de la revolución mexicana, y una estudiante erasmus apasionada por la cultura techno, que paso de vivir en un pequeño pueblo catalán a hacerlo en una de las capitales culturales del nuevo milenio - Berlín- inserta en la cultura juvenil global.
} 


\section{perifèria}

Número 5, Diciembre 2006

www.periferia.name

Barnet, M. 1970 (1979). La canción de Rachel, Barcelona, Laia.

Barret, S.M. 1906 (1975). Geronimo. Historia de su vida, Barcelona, Grijalbo.

Bertaux, D. 1993. "De la perspectiva de la historia de vida a la transformación de la práctica sociológica", in Marina \& Santamaría (eds): 19-34.

Bosio, G. 1963 (1975). "Elogio del magnetofono", in L'intellettuale rovesciato, Milano, Bella Ciao.

Bourdieu, P. 1989. "La ilusión biográfica", Historia y Fuente Oral, 2: 27-33.

Brandes, S. 1983. "Les autobiografies etnogràfiques en l'antropologia americana", Arxiu d'Etnografia de Catalunya, Tarragona, 2: 99-130.

Catani, M. 1973. Journal de Mohamed, Paris, Stock.

catani, M. 1993. "La historia de vida social como intercambio oral ritualizado", in Marinas \& Santamaría (eds): 257-266.

Catani, M. 1997. "Faim, mendicité, usure dans la 'Terre sans pain' et finalement, gastronomie", Ethnologie Française, 27 : 103-112.

Catani, M.; MAZÉ, S. 1982. Tante Suzanne. Une histoire de vie sociale, Paris, Librairie des Méridiens.

Cátedra, M. 1999. "Memorias del hambre", Revista de Libros, 25: 27.

Chalasinski, J. 1938. Mlode pokolenie chlopow (La joven generación polaca), Varsovia.

Clot, Y. 1989. "La otra ilusión biográfica", Historia y Fuente Oral, 2: 35-39.

Comas d'Argemir, D. et al. 1990. Vides de dona. Treball, família i sociabilitat entre les dones de classes populars a Catalunya (1900.-1960), Barcelona, Alta Fulla.

Contini, G. 1991. "La historia oral en Italia”, Historia y Fuente Oral, 5: 131-138.

Crapanzano, V. 1980. Tuhami. Portrait of a Moroccan, Chicago, Chicago University Press.

Crapanzano, V. 1985. Waiting. The Whites of South Africa, New York, Vintage.

de Martino, E. 1961 (1994) La terra del rimorso, Saggiatore, Milano.

de Miguel, J. 1996. Autobiografías, Madrid, CIS.

Devillard, M. J. et al. 2001. Los niños españoles en la URSS (1937-1997). Narración y memoria. Barcelona, Ariel.

Engels, F. 1845 (1979). La situación de la clase obrera en Inglaterra, Madrid, Júcar,

Feixa, C. 1987. "Més enllà d'Eboli. Gramsci i I'antropologia italiana", Nous Horitzons, Barcelona, 105: 28-41.

Feixa, C. 1990. Cultures juvenils, hegemonia i transició social. Una història oral de la joventut a Lleida (1936-1989), Barcelona, Universitat de Barcelona, Tesis Doctorals Microfitxades.

Feixa, C. 1992. La ciutat Ilunyana, Lleida, Nou Diari.

Feixa, C. 1998. De jóvenes, bandas y tribus, Barcelona, Ariel.

Feixa, C. 1998b. El reloj de arena: culturas juveniles en México, México, Ciejuv.

Feixa, C.; Agustí, C. 2003. "Los discursos autobiográficos de la prisión política”, en C. Molinero, M. Sala, J. Sobrequés (eds), Una inmensa prisión. Los campos de 


\section{perifèria}

Número 5, Diciembre 2006

www. periferia. name

concentración y las prisiones durante la guerra civil y el franquismo, Barcelona, Crítica: 199-230.

Feixa, C.; Espinosa, T. 2003. Allà des d'Aquí. 3 famílies, 3 orígens, 3 itineraris, Barcelona, Museu de Vilafranca-Urano Films (video).

Ferrarotti, F. 1981. Storia e storie di vita, Bari, Laterza.

Ferrarotti, F. 1986. La storia e il quotidiano, Bari, Laterza.

Frigolé, J. 1997. Un hombre. Género, clase y cultura en el relato de un trabajador, Barcelona, Muchnik.

Gamella, J.F. 1990. La historia de Julián, memorias de heroína y delincuencia, Madrid, Popular.

Gramsci, A. 1975 (1932-5). Quaderni del carcere, Torino, Einaudi.

Heizer, R.F.; Kroeber, T. (eds). 1979. Ishi the last Yahi. A documentary history, Berkeley, University of California Press.

Iniesta, M.; Villaró, A.; Feixa, C. 1991 (1997). 'Entre riu i lo bosc hi passàvem la vida'. El temps dels rais a la ribera del Segre, Tremp, Biblioteca Pirinenca.

Jimenez, A. 1978. Biografia de un campesino andaluz, Sevilla, Universidad de Sevilla.

Kroeber, T. 1984 (1961). Ishi, el último de su tribu, Barcelona, Antoni Bosch.

Langness, L.L.; Frank, G. 1985. Lives. An Anthropological Approach to Biography, Novato, Chandler \& Sharp

Lewis, O. 1961 (1981). Antropología de la pobreza. Cinco familias, México, FCE.

Lewis, O. 1964 (1971). Los hijos de Sanchez, Mexico, Moritz.

Lewis, O. 1986. Ensayos antropológicos, México, Grijalbo.

Maestre, J. 1976, Testimonio de un rebelde, Madrid, Cuadernos para el Diálogo.

Marinas, J.M.; Santamaria, C. (eds). 1993. La historia oral. Métodos y experiencias, Madrid, Debate.

Marsal, J.F. 1972. Hacer la América. Biografía de un emigrante, Barcelona, Ariel.

Mills, C. W. 1959 (1977). La imaginación sociológica, México, FCE.

Passerini, L. 1984. Torino operaia e fascismo: una storia orale, Roma-Bari, Laterza.

Passerini, L. 1988. Autoritratto di gruppo, Firenze, Giunti.

Plumer, K. 1983 (1989). Los documentos personales, Madrid, Siglo XXI.

Portelli, A. 1985. Biografia di una città, Terni, storia e racconto. 1830-1985, Torino, Einaudi.

Portelli, A. 1989. "Historia y memoria. La muerte de Luigi Trastuli", Historia y Fuente Oral, 1: 5-33.

Portelli, A. 1989b. The Death of Luigi Trastulli and Other Stories, Albany, State University of New York Press.

Pozas, R. 1952 (1975). Juan Pérez Zolote: autobiografía de un totzil, México, FCE.

Prat, J. 1998. El estigma del extraño, Barcelona, Ariel.

Pujadas, J.J. 1992. El método biográfico: el uso de las historias de vida en ciencias sociales, Madrid, CIS. 


\section{perifèria}

Número 5, Diciembre 2006

www.periferia.name

Romaní, O. 1983. A tumba abierta. Autobiografía de un grifota, Barcelona, Anagrama.

Romaní, O. 1984. "Les històries de vida: algunes consideracions sobre les relacions informant-investigador", Col.loqui sobre les Fonts Orals, Palma de Mallorca.

Romaní, O.; FUNES, J. 1985. Dejar la heroína, Madrid, Ministerio de Trabajo y Seguridad Social.

Shaw, C.R. 1930 (1966). The Jack-Roller, Chicago, University of Chicago Press.

Simmons, L.W. 1942 (1979). Sun Chief, New Haven, Yale University Press.

Szczepanski, J. 1978. "El método biográfico", Papers, 10: 229-256.

Terradas, I. 1991. "La historia de las estructuras y la historia de la vida", in J.Prat et al. (eds), Antropología de los pueblos de España, Madrid, Taurus.

Terradas, I. 1992. Eliza Kendall. Reflexiones sobre una antibiografía, Bellaterra, UAB.

Thomas, W.I.; Znaniecki, F. 1918-20 (1978). The Polish Peasant in Europe and America, New York, Dover.

Vansina, J. 1967. La tradición oral, Barcelona, Labor.

Vendrell, J. 1999. Pasiones ocultas, Barcelona, Ariel.

Vinyes. R. 1998. El soldat de pandora. Una biografia del segle XX, Barcelona, Proa

VV.AA. 2001. Explica'ns la teva vida, Barcelona, Edicions 62-TV3.

VV.AA. 2002. Els nens perduts del franquisme, Barcelona, Proa-TV3.

Zaretsky, E. 1984. "Introduction", in Thomas \& Znaniecki: 1-58.

Zorbaugh, H. 1929. The Gold Coast and the Slum, Chicago, University of Chicago Press. 